\section{Cahiers de Narratologie}

Analyse et théorie narratives

29 | 2015

Street Art 1

\title{
Le Street Art aux Petites Antilles Françaises
}

\section{Anne-Catherine Berry}

\section{OpenEdition}

\section{Journals}

Electronic version

URL: http://journals.openedition.org/narratologie/7413

DOI: 10.4000/narratologie.7413

ISSN: 1765-307X

\section{Publisher}

LIRCES

\section{Electronic reference}

Anne-Catherine Berry, "Le Street Art aux Petites Antilles Françaises », Cahiers de Narratologie [Online] 29 | 2015, Online since 20 January 2016, connection on 01 May 2019. URL : http:// journals.openedition.org/narratologie/7413; DOI : 10.4000/narratologie.7413

This text was automatically generated on 1 May 2019.

Article L.111-1 du Code de la propriété intellectuelle. 


\section{Le Street Art aux Petites Antilles Françaises}

\section{Anne-Catherine Berry}

1 Depuis quelques années, des pratiques artistiques s'inscrivant dans la tendance du Street Art émergent aux Antilles (1).

(1)

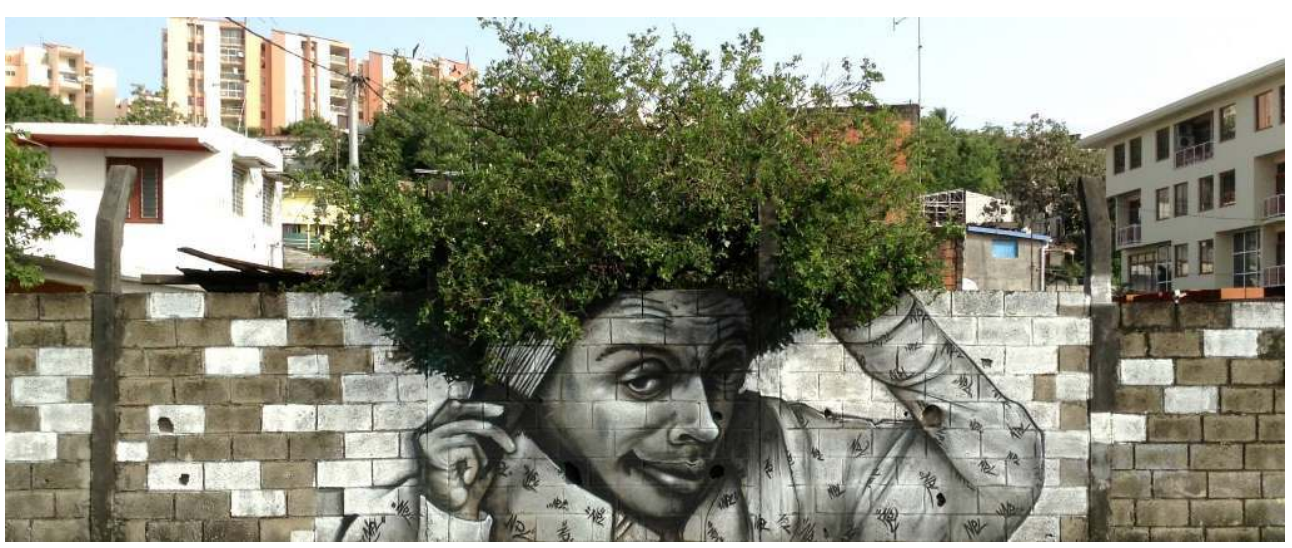

2 Les graffitis, les peintures murales, les collages font l'objet d'interventions ponctuelles, isolées. Même si ces pratiques se font rares, elles n'en sont pas moins en forte résonnance avec leur région et ses spécificités.

3 Ce contexte régional, que nous pourrions qualifier de complexe, laisse transparaitre chez certains artistes une démarche engagée. Il va sans dire que tant du point de vue de leurs partis pris plastiques que de celui des enjeux de leurs interventions, les problématiques qui semblent en émerger s'appuient sur une réflexion en lien avec l'idée d'une identité antillaise. Cette notion d'identité est complexe, d'autant plus ici, étant donné la configuration insulaire de ces régions qui se singularise par une culture plurielle. 
Ce concept de «société plurielle» né de rencontres croisées, est caractéristique des Petites Antilles qui, rappelons-le, font partie de la Caraïbe. Dominique Chancé écrit à ce sujet: «la conscience d'être antillaises n'est pas une évidence pour ces îles qui ont été avant tout des territoires coloniaux ${ }^{1} »$. Elles vivent ainsi relativement isolées les unes des autres pour des raisons multiples, tant économiques que politiques et linguistiques. Toutefois, elles demeurent unies par la géographie, l'insularité, le bassin de la mer des Caraïbes et ses particularités climatiques, ses paysages et autres aspects; différents arguments qui leur confèrent une certaine force. Elles constituent ainsi ce que nous pouvons désigner comme une communauté, ou encore un archipel, une structure à la fois éclatée et cohérente, avec des similitudes en nombre, mais surtout elles sont un étonnant laboratoire de la diversité culturelle. Le Clézio écrit à ce propos : « Il y a un esprit des îles comme il y a un esprit des montagnes ou un esprit des forêts ${ }^{2}$ ». L'identité caribéenne est ainsi faite, forgée par l'écho de cette insularité, le métissage des peuples, des langues et des histoires.

5 Nous pouvons alors reconnaître que les identités créoles se sont construites au fil d'un brassage des quatre continents: Afrique, Amérique, Europe et Asie. Les traces écrites d'Aimé Césaire, Edouard Glissant, mais aussi de Patrick Chamoiseau, Daniel Maximin, Raphaël Confiant, et tant d'autres nous le rappellent en permanence. Quatre continents qui se rencontrent, se croisent, générant ainsi un monde nouveau, en devenir, en constante évolution, véritable synthèse d'épisodes historiques, culturels, sociaux, etc. Ce métissage imprègne et génère toute la culture créole et se retrouve dans les pratiques artistiques.

6 Une œuvre singulière ne peut être dépourvue de références. Elle se distingue alors par des techniques diverses autant que par des matériaux et supports variés. L'œuvre d'art antillaise entretient un lien particulier avec son environnement (physique et immatériel), un rapport singulier au lieu. Ainsi les éléments dont l'artiste use (qu'ils soient plastiques ou sémantiques) sont porteurs d'une signification liée à ce lieu d'où ils proviennent. Ces images, objets ou matériaux sont, par essence, chargés d'une force et sont marqueurs d'une trace, d'une mémoire. Ces fragments, choisis par l'artiste, représentent des signes qu'il mettra en relation afin d'exprimer une idée. C'est la rencontre de ces signes qui fera sens.

7 Nous pourrions alors nous poser la question de savoir comment des artistes, en Guadeloupe et en Martinique, s'inscrivant dans une pratique du Street Art, rendent-ils compte des spécificités de la culture antillaise.

8 Ces artistes investissent des surfaces, murs, façades de maisons, essentiellement, comme pour rendre visible, révéler, des vérités. Ils semblent vouloir faire resurgir les affres d'une culture, d'une histoire, d'une mémoire collective. Ainsi, leurs interventions, quels que soient leur nature, leur forme et leurs enjeux véritables, se révèlent comme une seconde peau, un film révélateur, laissant suinter hors des murs opaques l'indicible ou simplement la singularité. Désormais le support, ici dans son sens le plus large, ne contribue plus uniquement à la réalisation de l'œuvre, mais fait œuvre véritablement, participant à la pensée de celle-ci, à sa mise en forme, également à sa réception. Quelles que soient les aspirations de l'artiste ou la portée de son intervention, que celle-ci soit provocatrice ou non, elle se compose au rythme des pulsations de la Cité, et sous le regard des usagers.

9 Pour appréhender au mieux la question, il sera intéressant d'entrevoir dans quelles conditions cette tendance artistique contemporaine apparait dans les deux îles et sous 
quelles formes elle s'y développe. Nous pourrons ainsi comprendre quelles sont les aspirations et les préoccupations de ces artistes et comment ils se situent dans une pratique qui se veut parfois subversive, et d'autres fois autorisée voire commanditée.

En ce qui concerne le graffiti, nous observons dans les deux îles un ancrage indéniable dans la culture hip hop telle que nous la connaissons à l'origine. Ce sont les mêmes codes et fonctionnements, mais aussi une amorce progressive des évolutions qui marquent cette culture depuis quelques années. Ainsi les pratiques se déclinent-elles et s'adaptent-elles également sur ces territoires. Nous devons alors distinguer les graffs (libre expression) des fresques murales (décoration). En Guadeloupe, de nombreuses communes portent les traces et les témoignages de ces pratiques. Un certain nombre de graffeurs sont concernés, ils appartiennent à quelques crew : 4KG, RN5, M16, BCP, KSA, TRM, QCP, CAF, FDP, pour exemples. Les municipalités voire la Région Guadeloupe et /ou le Conseil Général sollicitent certains de ces artistes afin d'apporter une nouvelle dynamique à leur territoire. Le paysage urbain devient ainsi la toile de fond de peintures variées.

Pwoz est l'une des figures emblématiques du graffiti guadeloupéen et ce depuis une vingtaine d'années. Il est connu pour ses illustrations de scènes quotidiennes locales (2) ou de la nature luxuriante (3-4) qui recouvre en partie l'île et qu'il élève au rang de véritable patrimoine (5). Il est le premier à initier la fresque murale à l'échelle des façades de bâtiments (6). Il distingue sa pratique de graffeur de sa pratique de la fresque murale, il considère celle-ci comme étant plus de l'ordre du décoratif et de l'éducatif, visant une amélioration du cadre de vie des habitants des cités notamment. Ce projet semble-t-il aurait été suggéré par les habitants eux-mêmes.

(2)

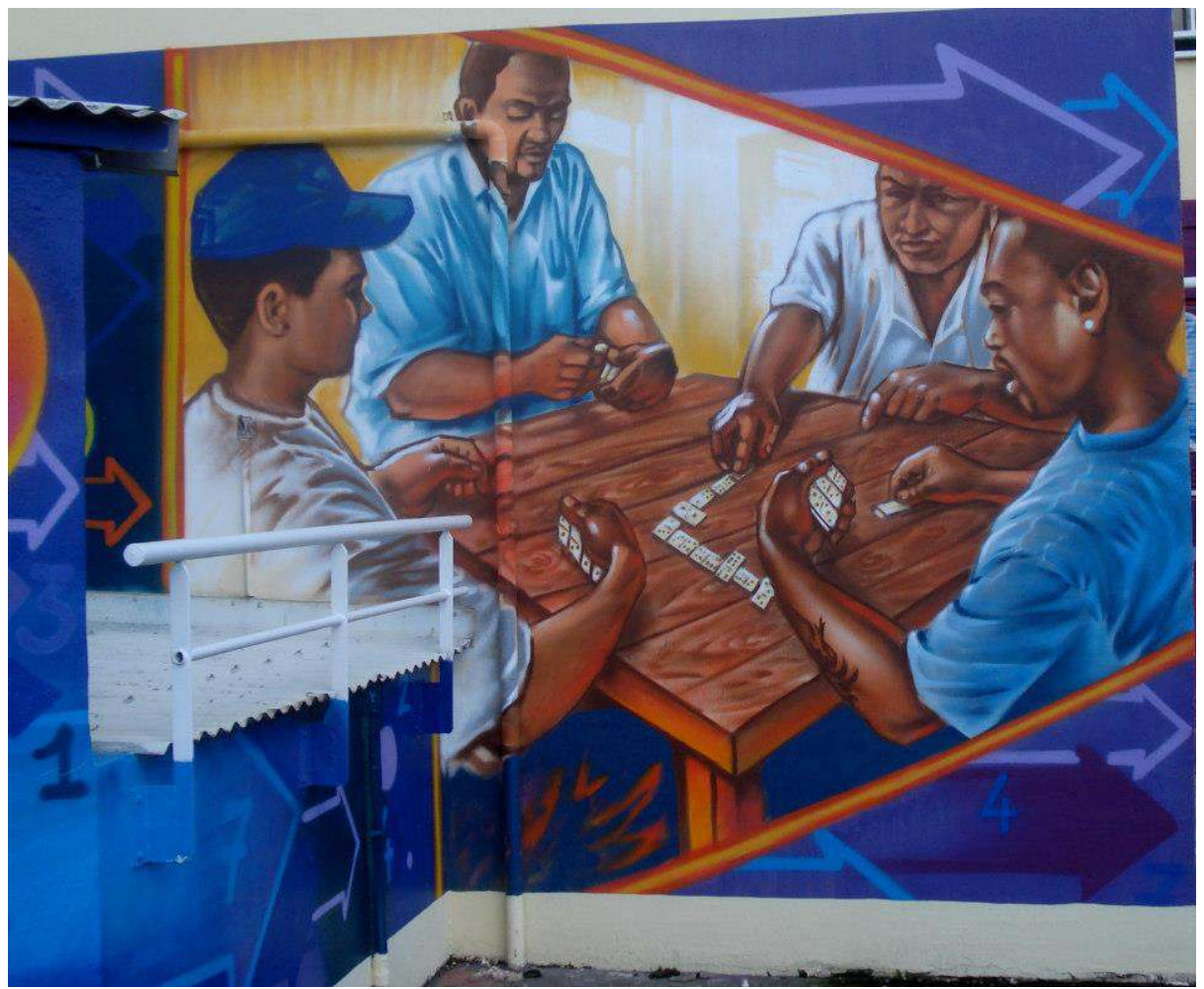


(3)

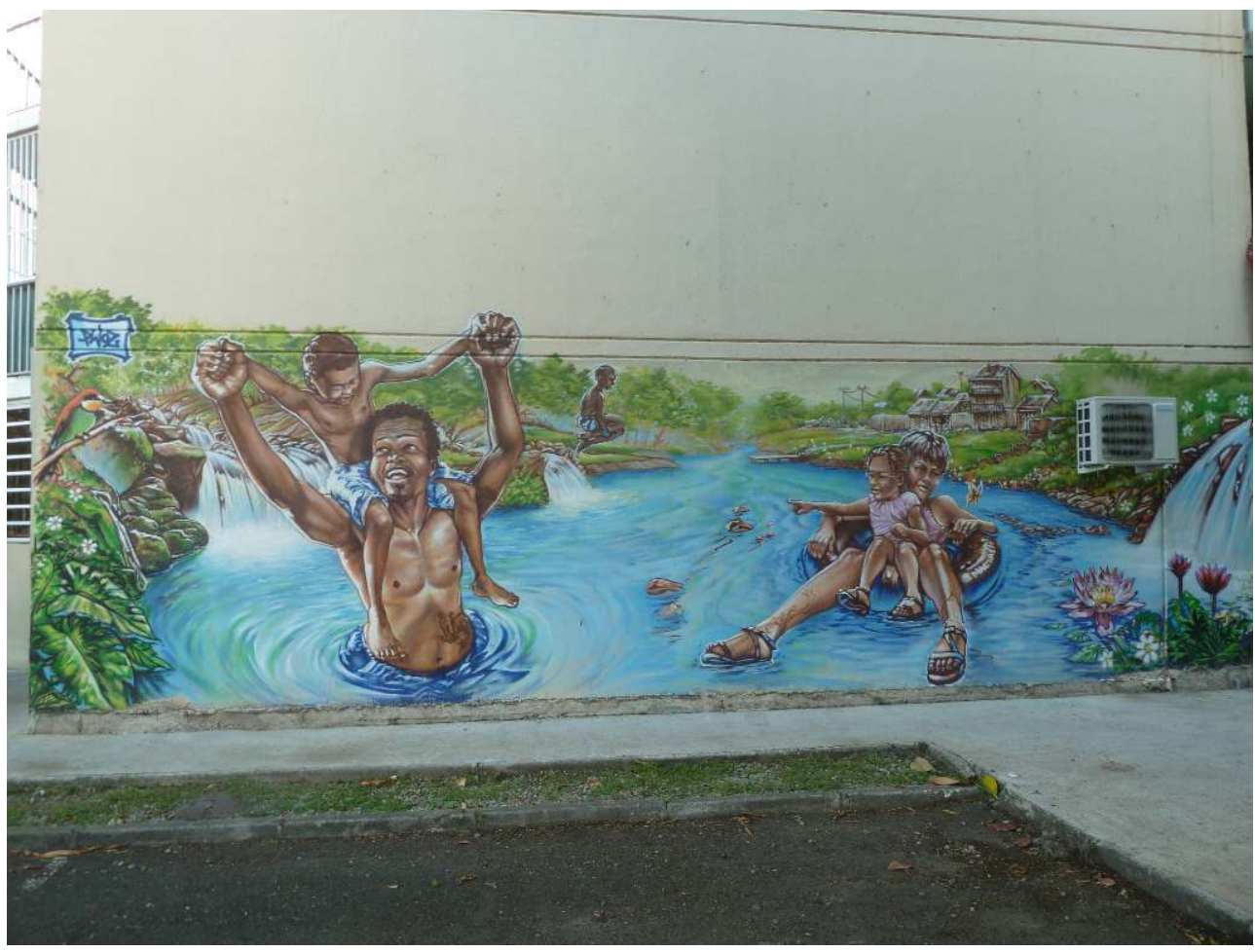

(4)

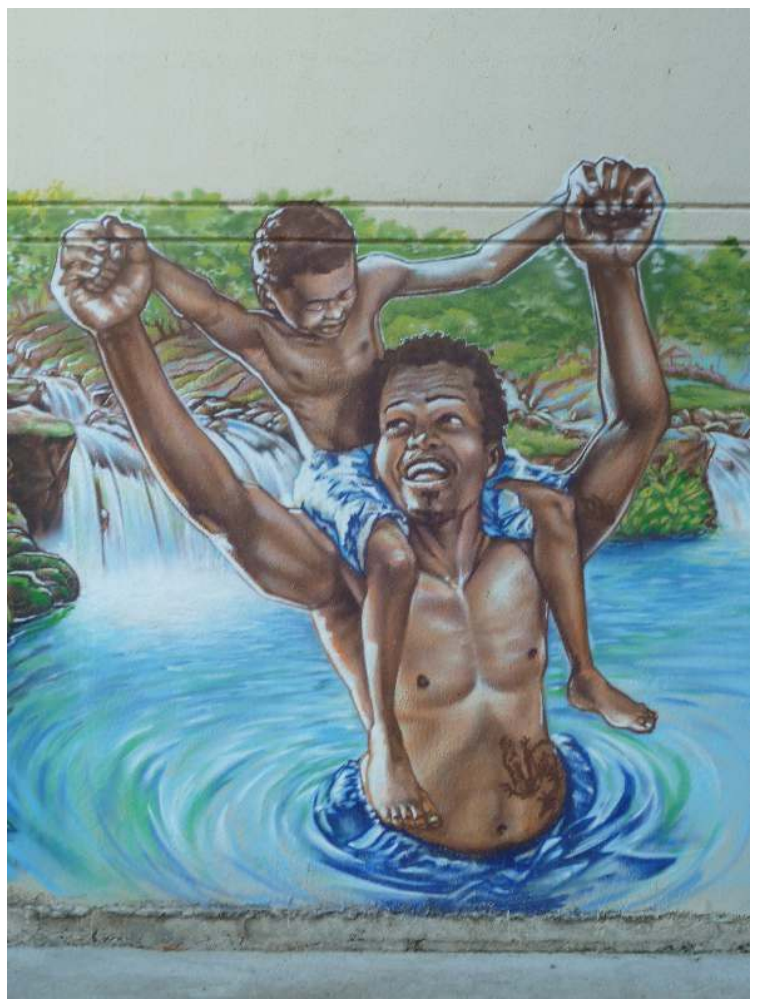


(5)

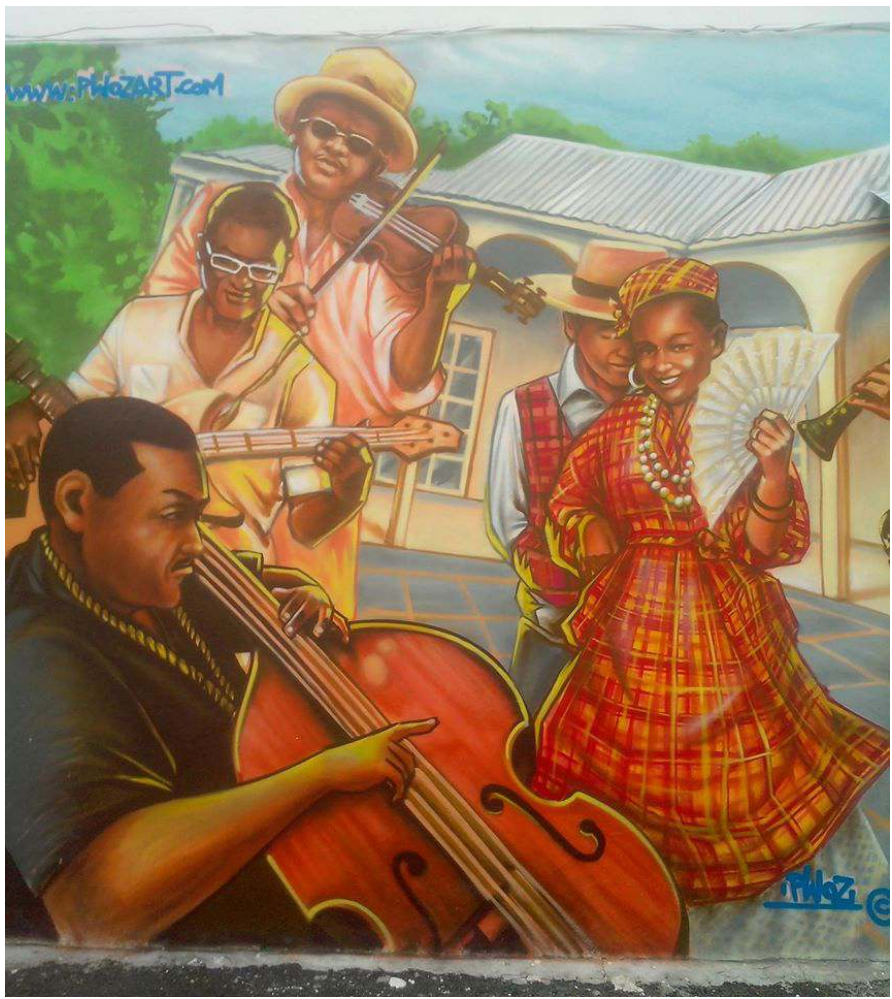

(6)

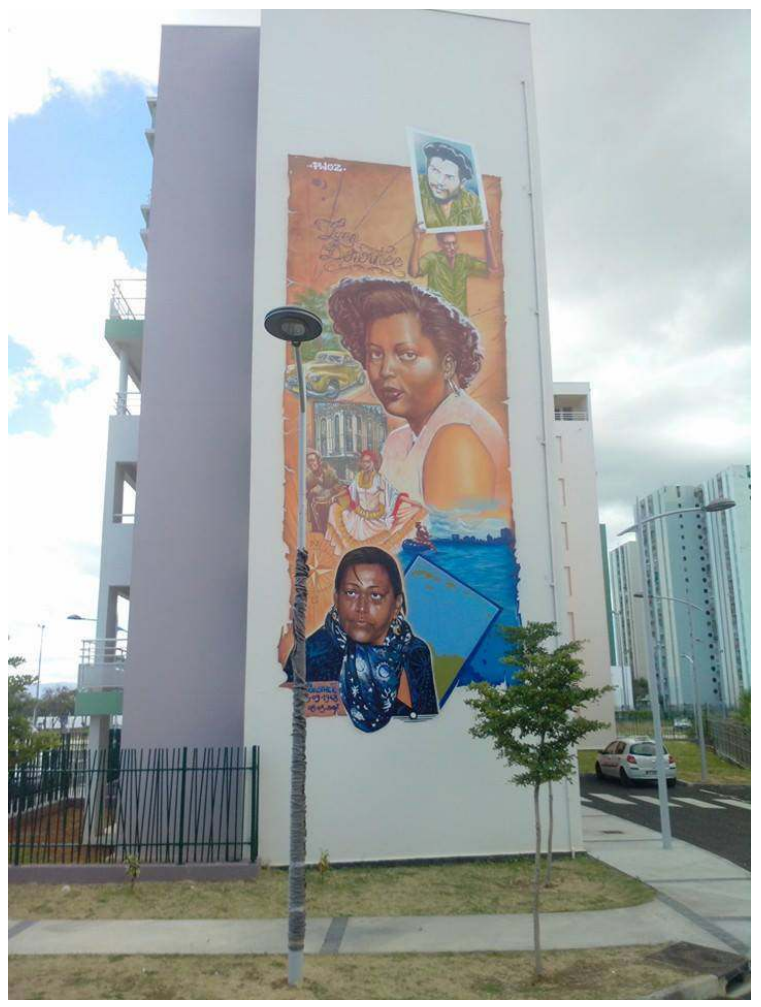

4KG est une association de quatre artistes : Myki, Nywo, Tryspa et Yeswo, dont l'acronyme signifie « 4 Kouleurs Grafik » en lien aux quatre couleurs utilisées dans l'imprimerie (7-9). 
(7)

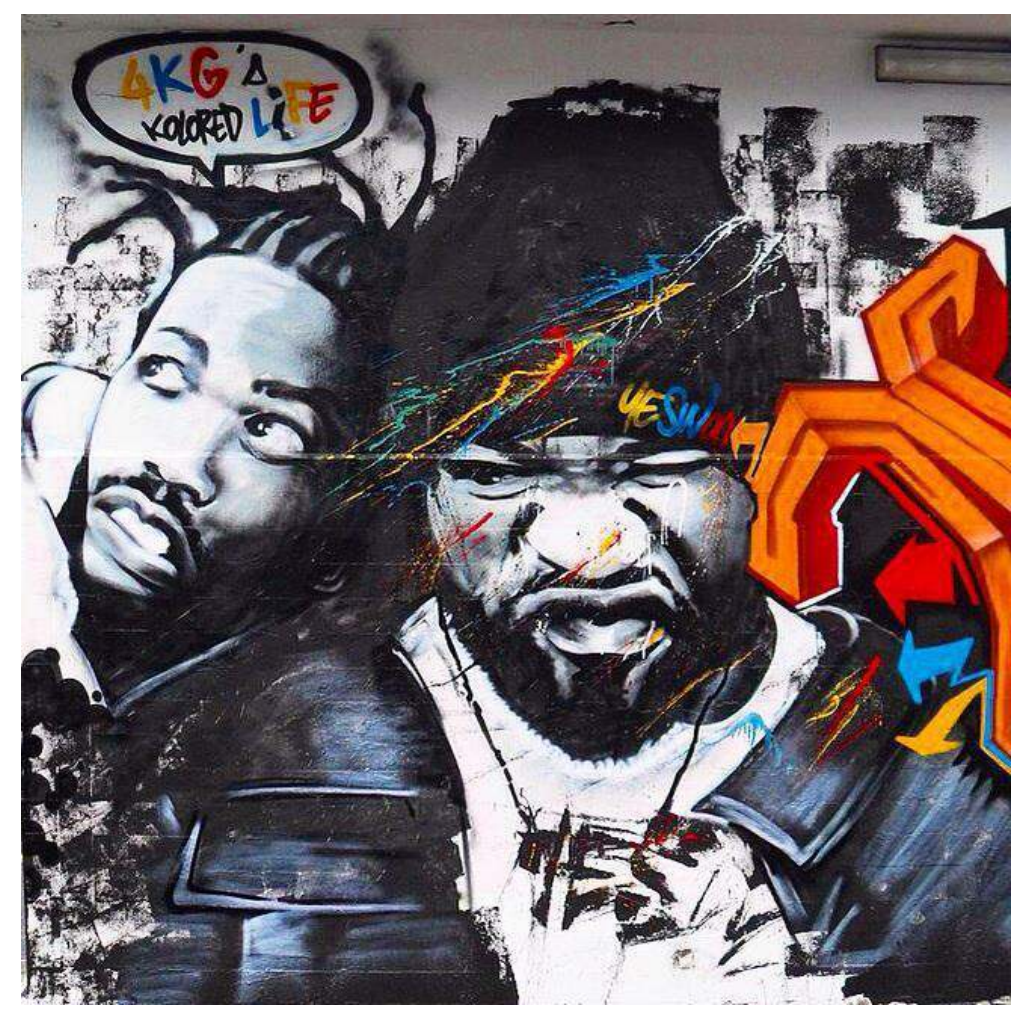

(8)

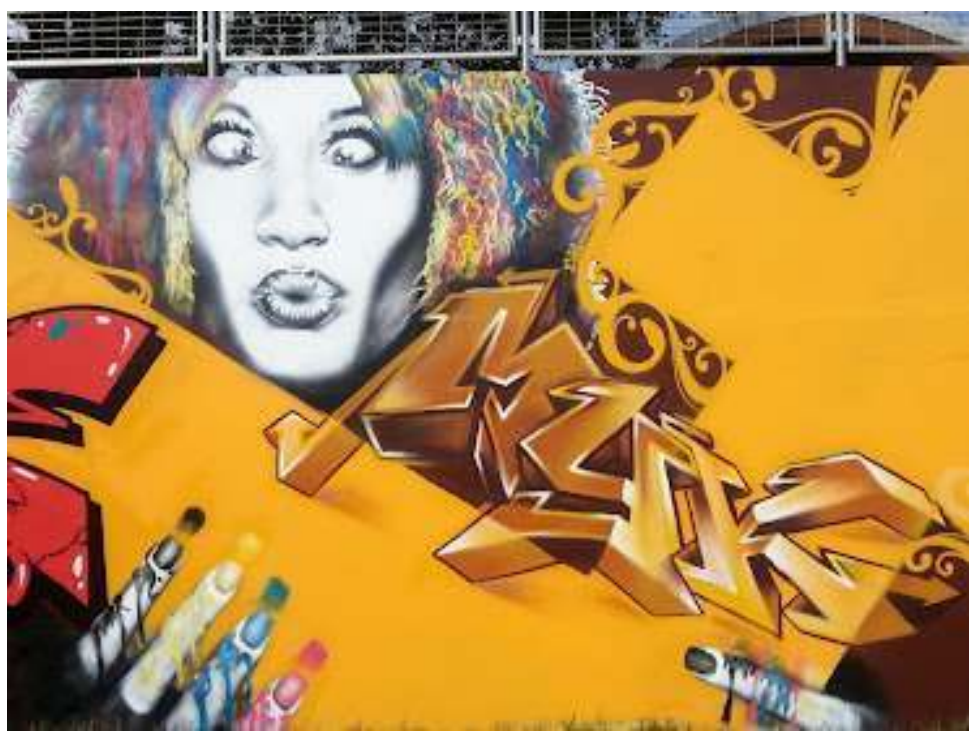


(9)

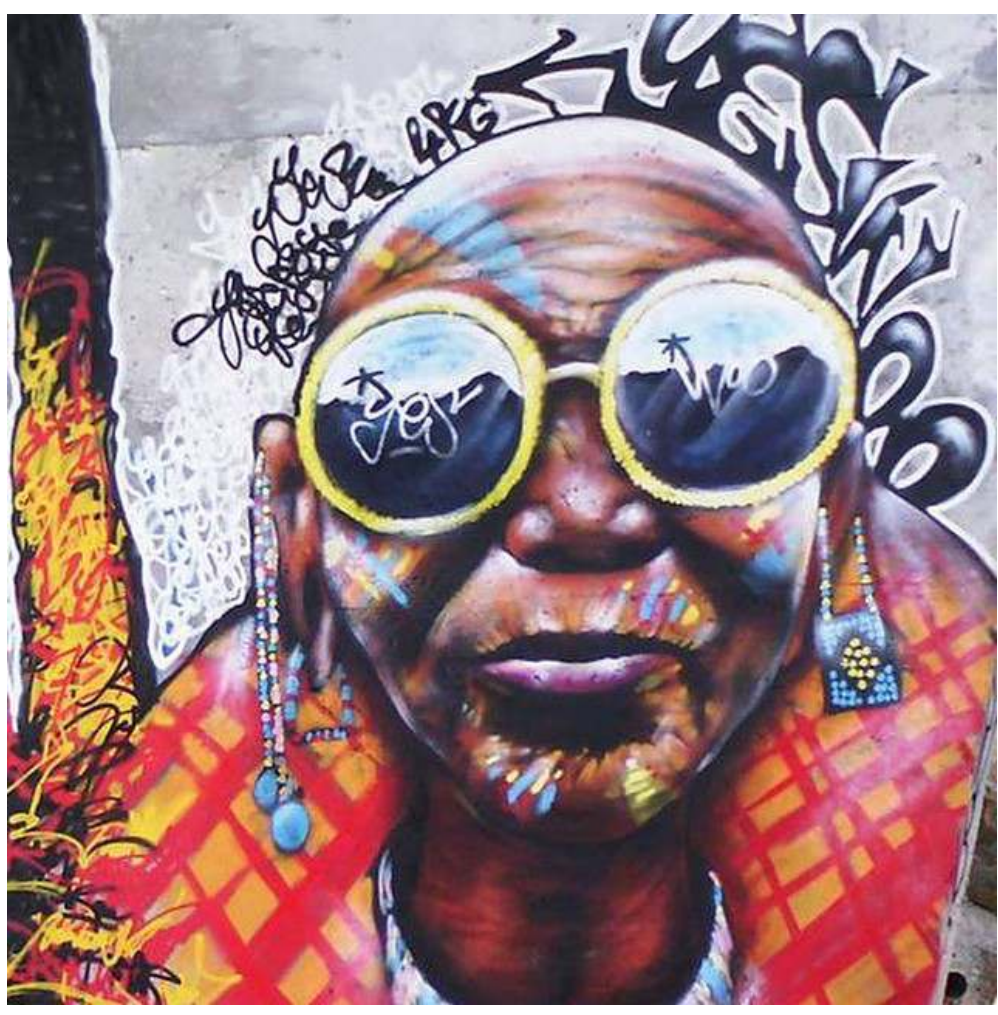

Ce groupe se compose donc de quatre artistes, quatre couleurs, quatre styles qui se combinent dans une certaine unité. On observe une volonté d'un retour aux sources en allant à la rencontre de certains grands noms et hauts lieux du Graffiti aux Etats-Unis. Un film ${ }^{3}$ peut en témoigner, mais ils sont également animés par un désir de rencontrer d'autres artistes et d'autres lieux de cette scène artistique. Par exemple le projet dit Nomade s'organisant comme une sorte de Block party itinérante prend l'allure d'un voyage initiatique et d'échanges (Brésil, Belgique, Amsterdam, USA, Polynésie...). Toutefois, nous ne pouvons ignorer l'imprégnation de leur pratique par leur environnement immédiat. Le caractère de celui-ci contamine et habite sans équivoque leurs réalisations, que ce soit du point de vue de leur support, formes, couleurs, sujets, ou styles. Leurs créations sont imprégnées de leur histoire individuelle, mais également d'une histoire collective (10-14). 
(10)

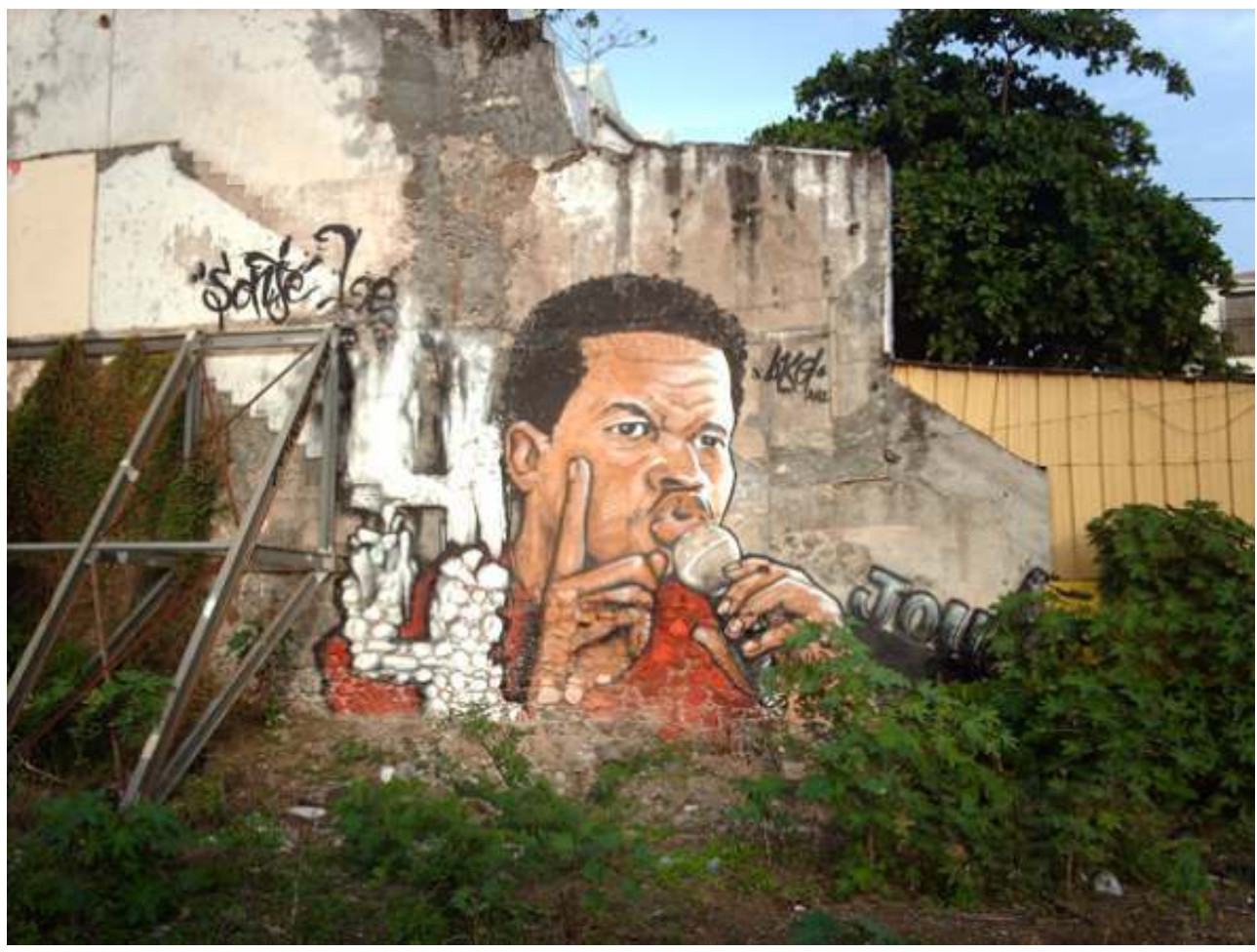

(11)

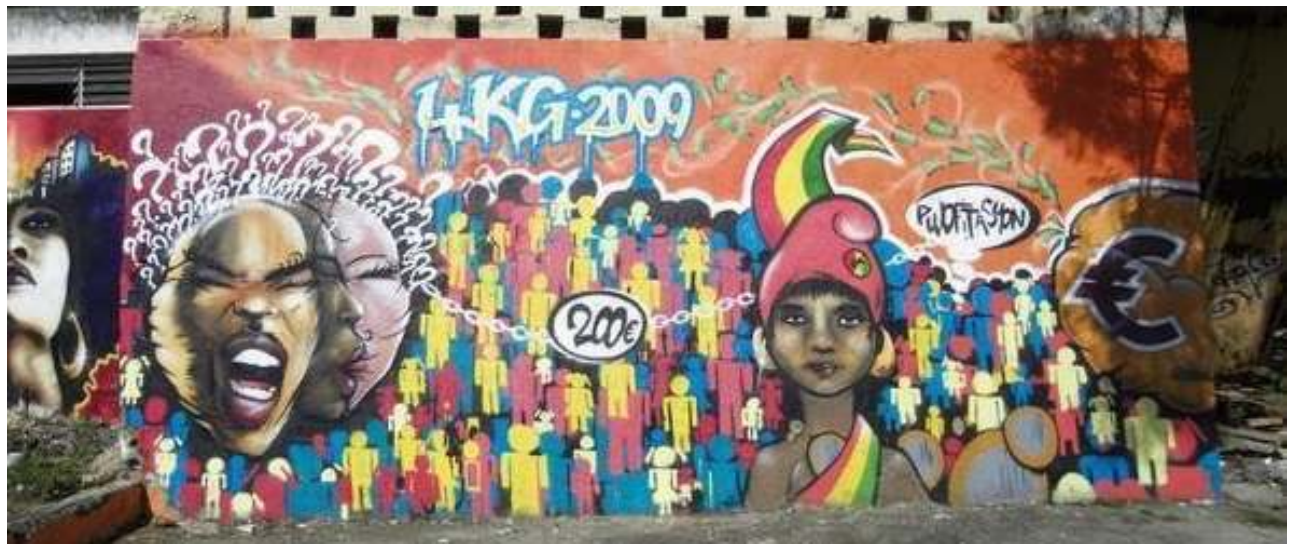


(12)

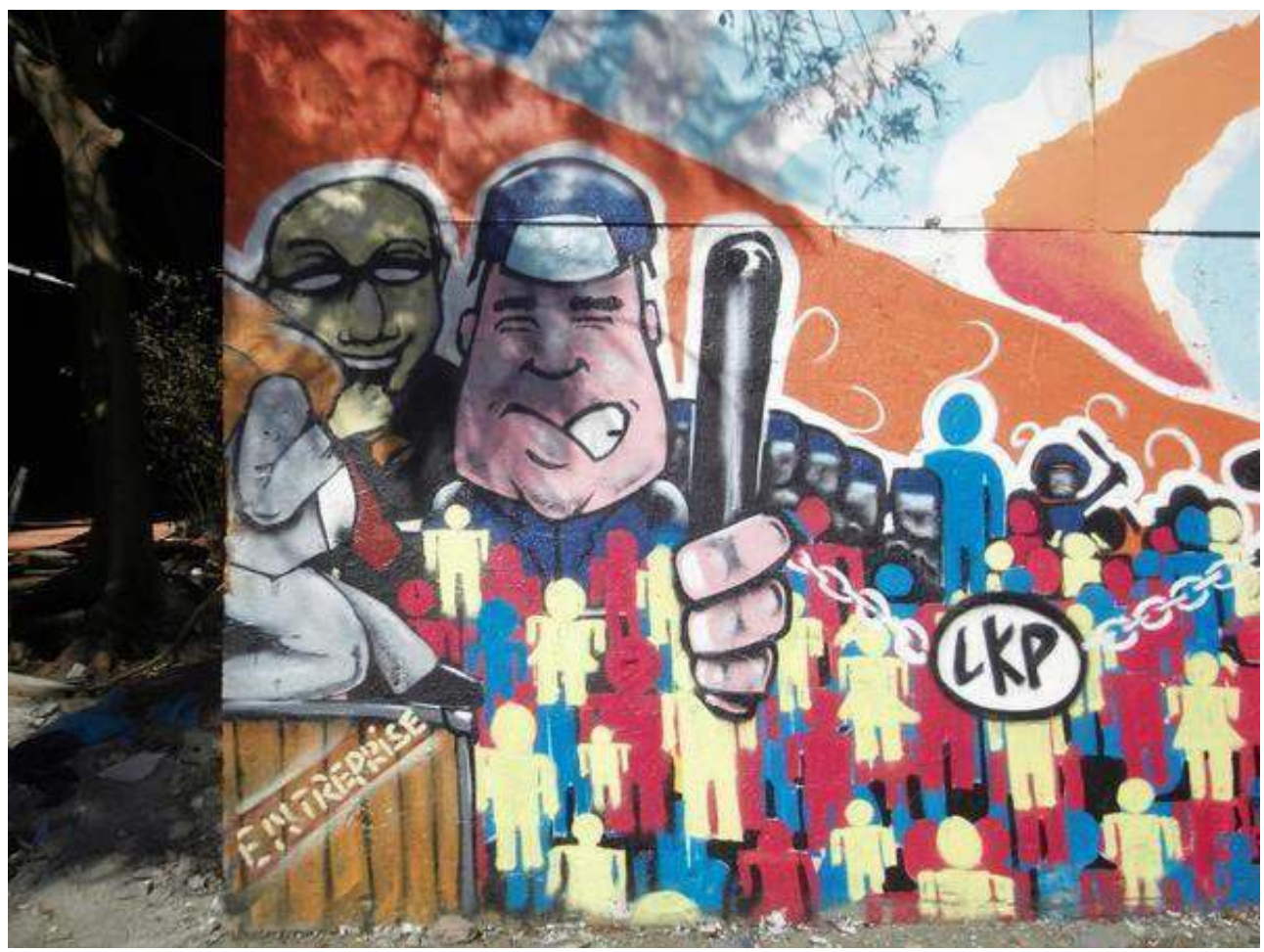

(13)

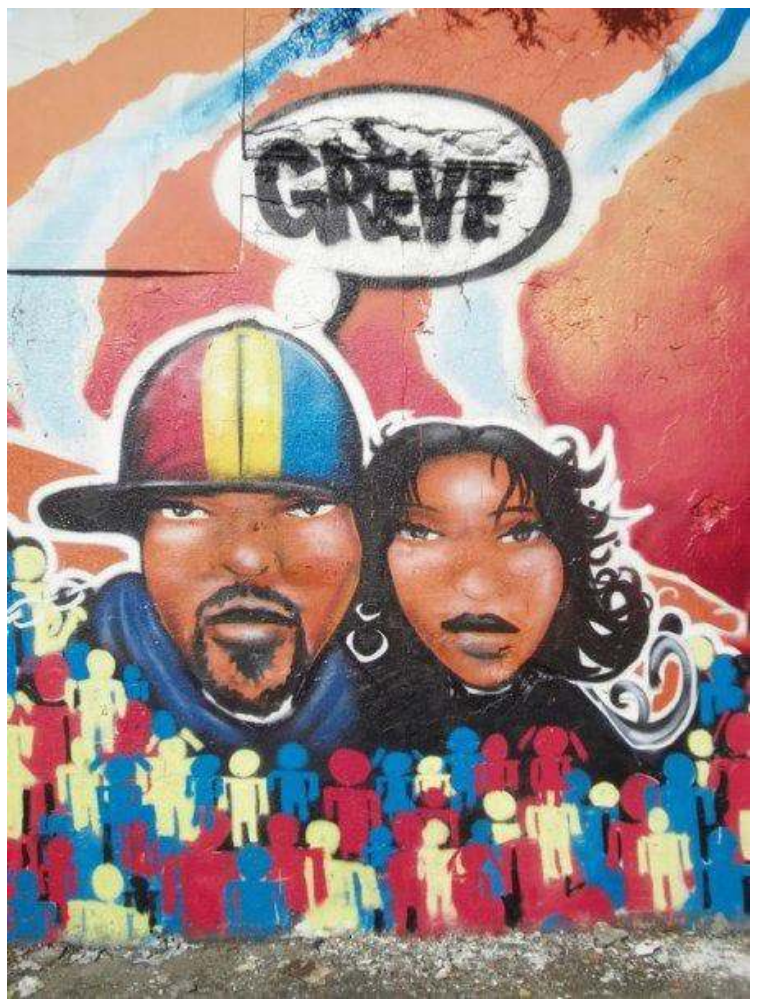


(14)

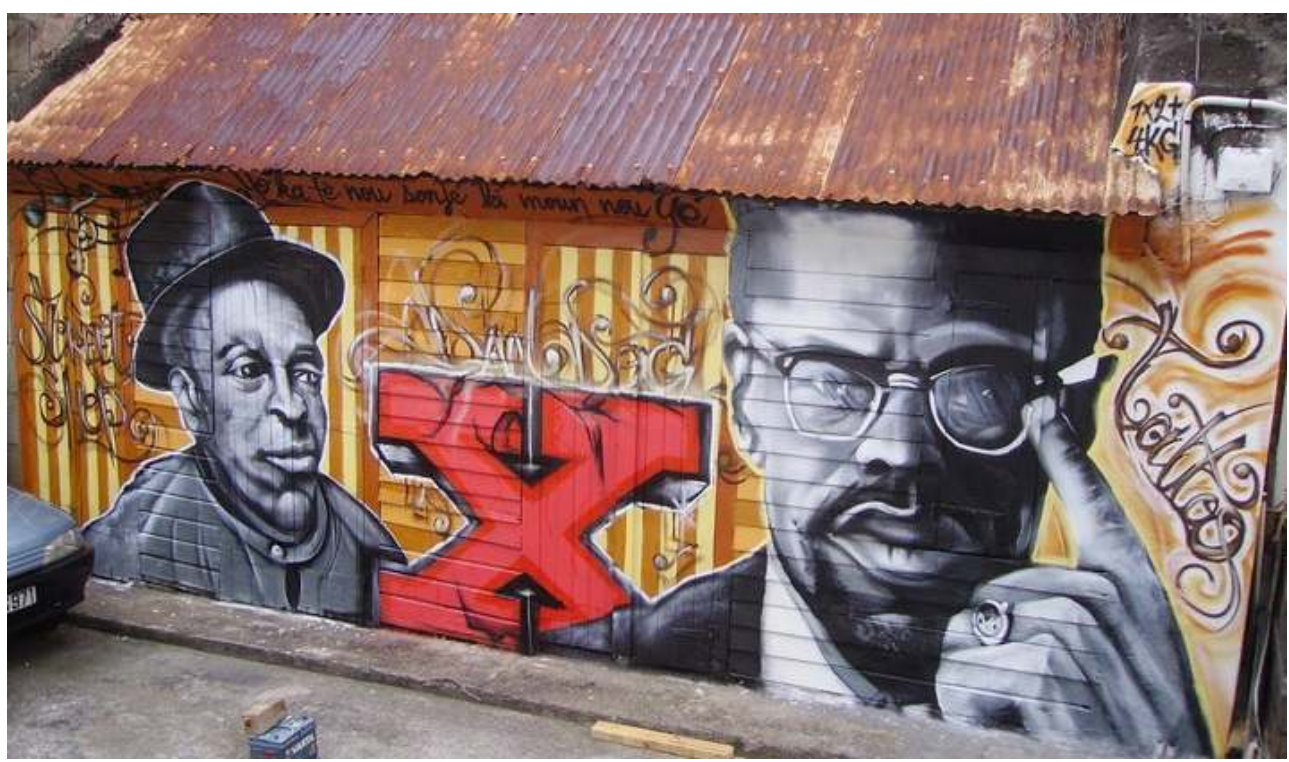

En Martinique, on observe quelques similitudes, à la différence toutefois d'une reconnaissance moindre des collectivités, ce qui rend les réalisations d'envergure bien moins nombreuses sur le territoire. D'ailleurs les artistes intervenant dans le milieu urbain sont moins nombreux. Ceux qui occupent cette scène sont essentiellement les graffeurs du collectif Madapaint ${ }^{4}$ dont chacun des membres, là encore, détient sa propre palette, son propre style, son propre univers. Parmi les plus actifs on compte aujourd'hui : Rman, James, Oshea, Xan, Wiltho. Cela dit, ils ont tous en commun le même contexte culturel et la mise en valeur du patrimoine culturel martiniquais à différents niveaux de lecture. Oshea systématise la représentation d'un personnage portant les attributs du Martiniquais par excellence, (15-16) une peau brune, un chapeau bakoua (chapeau de paille typique), un vêtement ou un décor de fond arborant les teintes du tissu madras (vert, orange, jaune, etc.), (17) emblématique de la présence et de l'apport de l'indianité dans la culture créole (18-20). Xan, quant à lui, produit inlassablement des portraits, (21-23) des visages tous différents les uns des autres dont certains sont pensés spécifiquement pour le lieu de réalisation. (24-25) Il intègre la figure peinte au support environnant de cette peinture, ainsi le cerisier derrière le mur devient-il la chevelure de Spike Lee (26) (mise en valeur de la culture noire contemporaine favorisant le port du cheveu naturel). Ses figures sont la plupart du temps imprégnées des types ethniques que nous pouvons rencontrer sur l'île. 
(15)

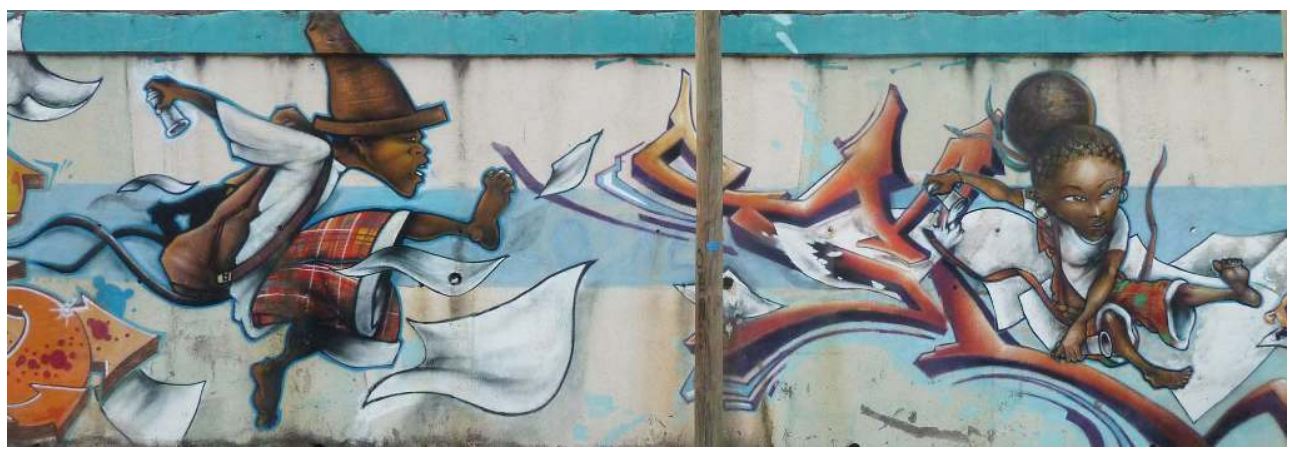

(16)

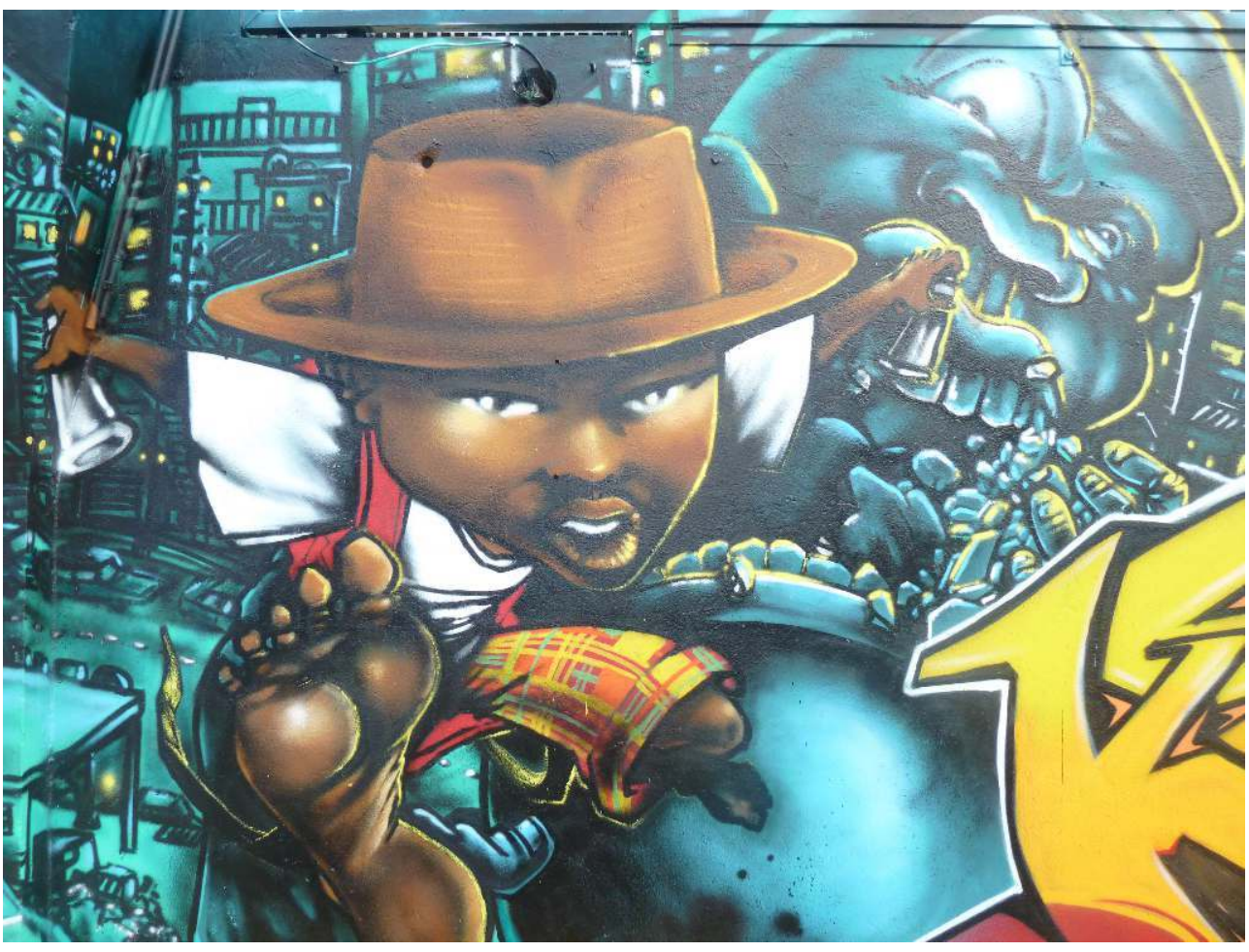

(17)

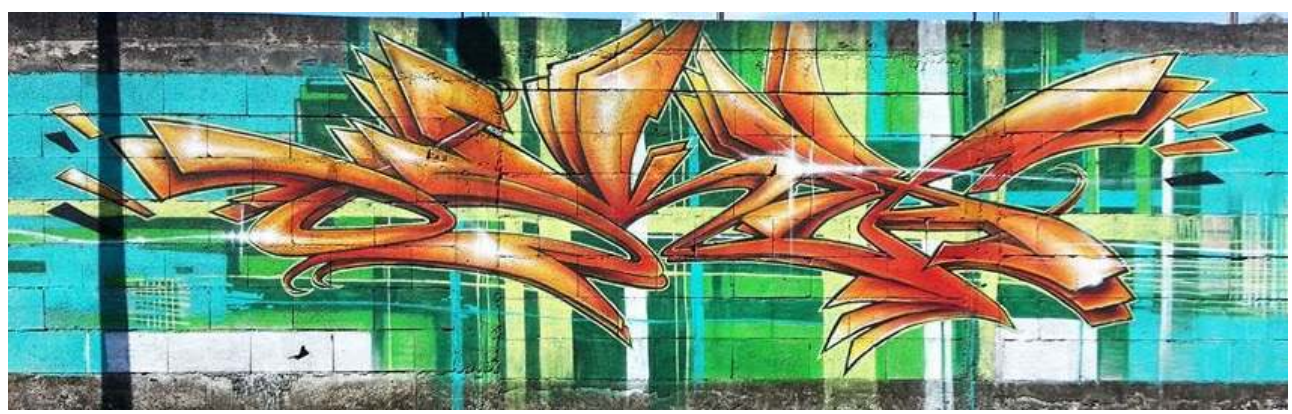


(18)

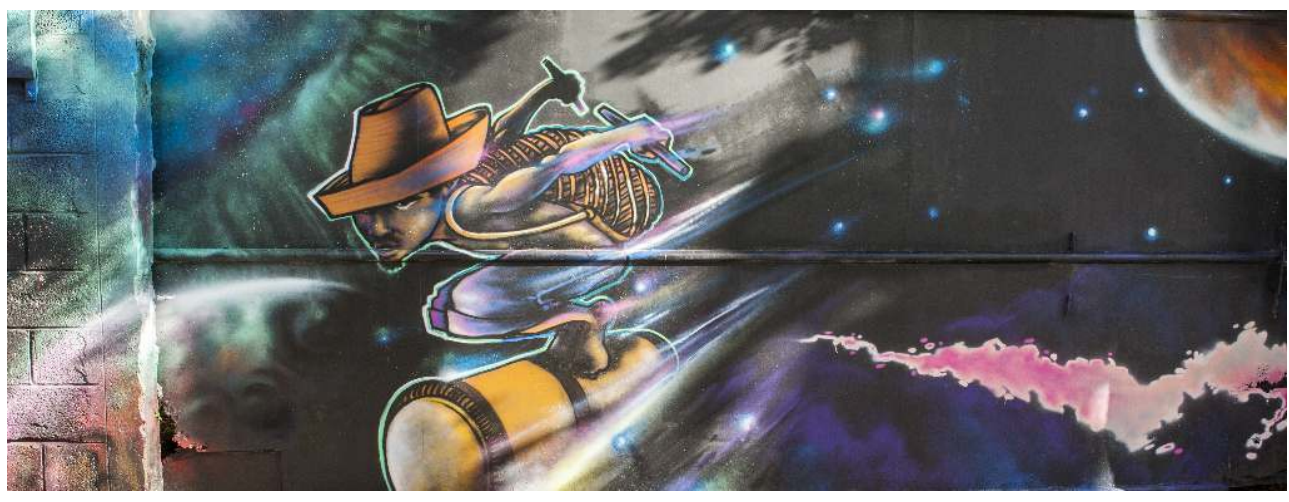

(19)

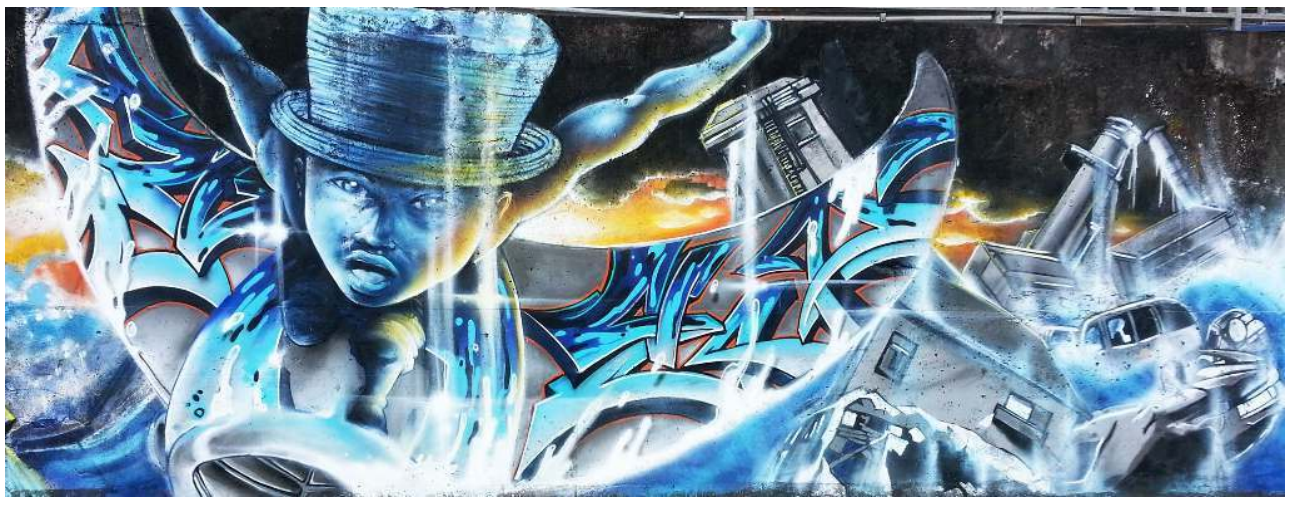

(20)

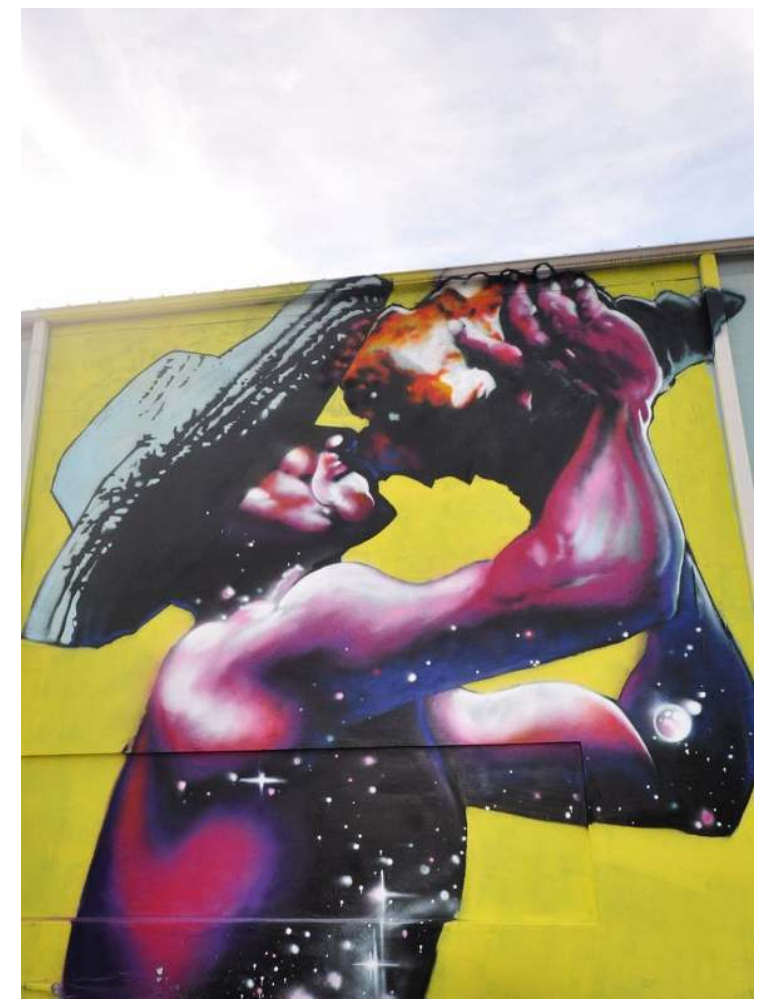


(21)

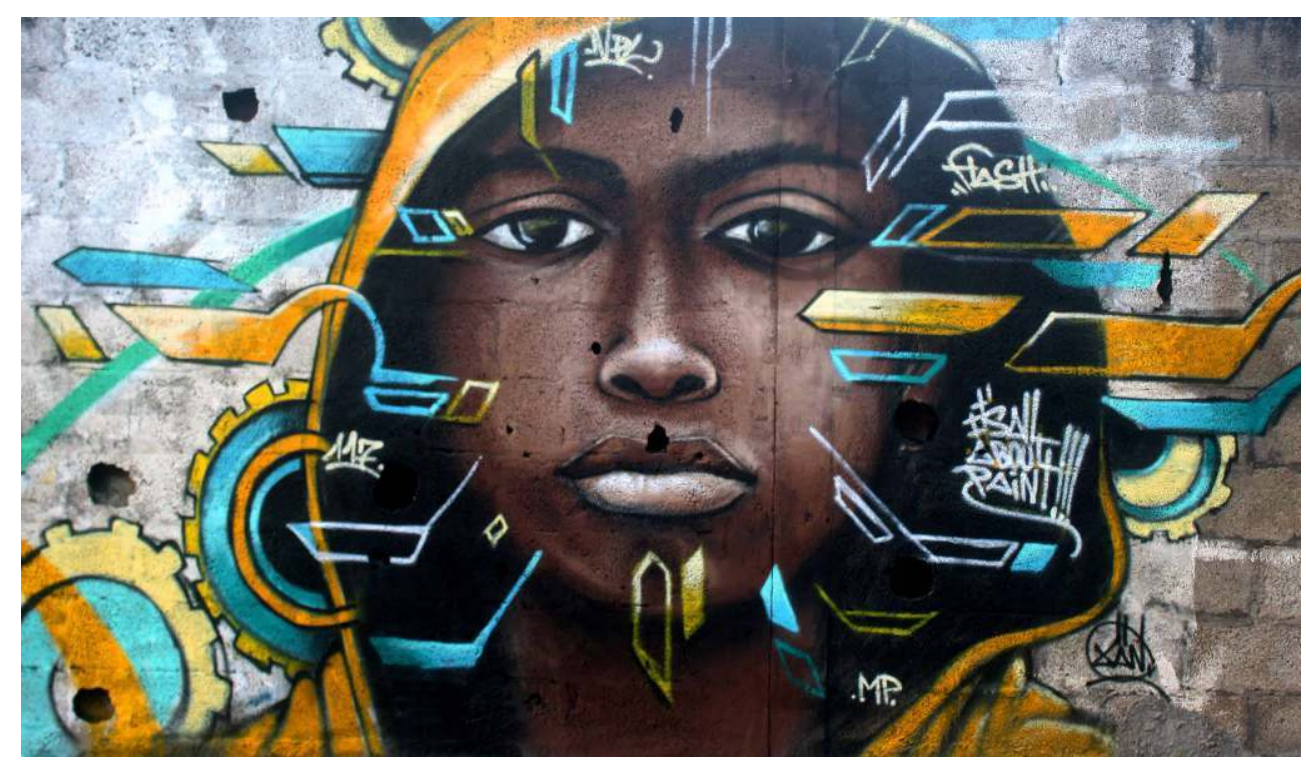

(22)

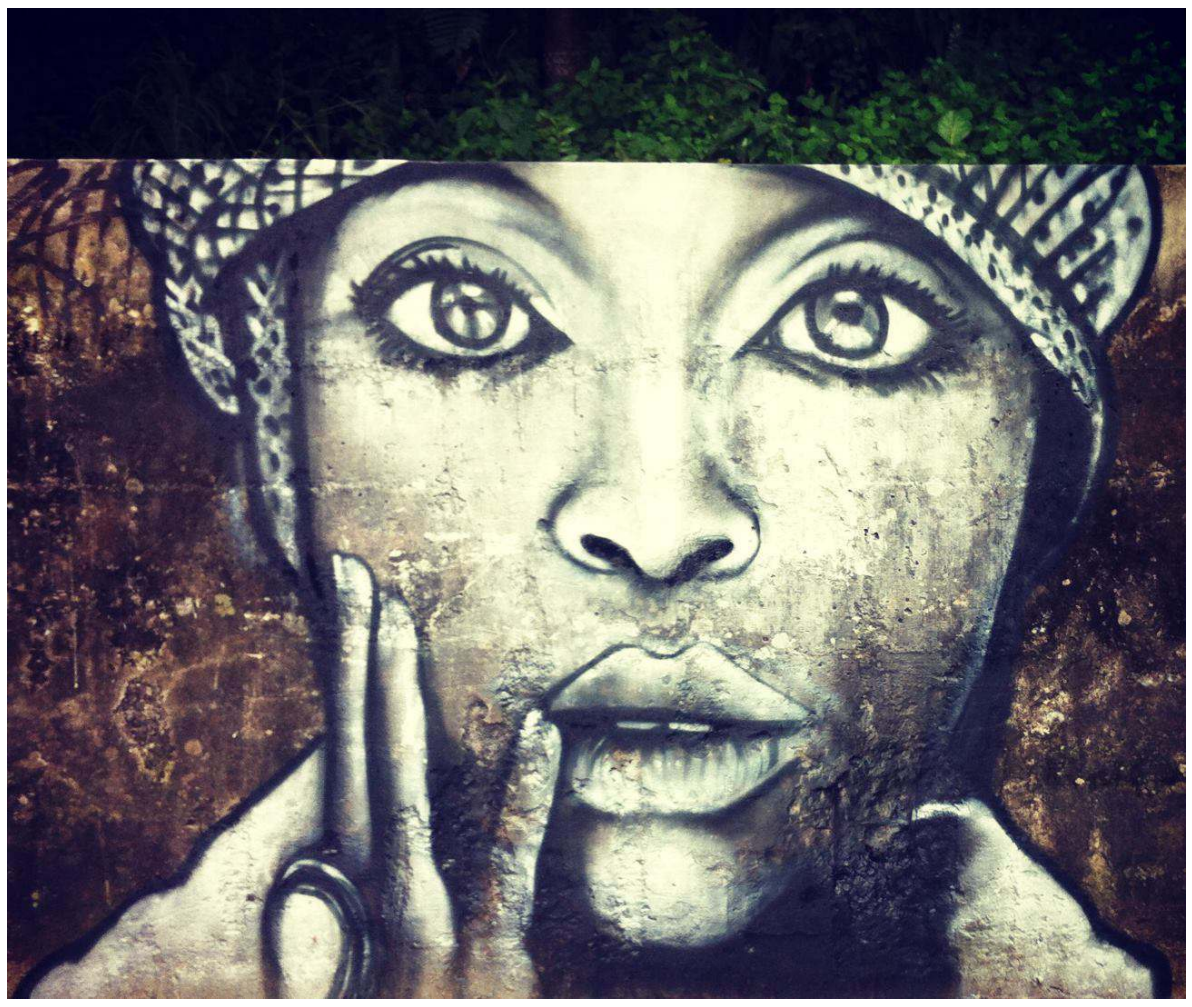


(23)

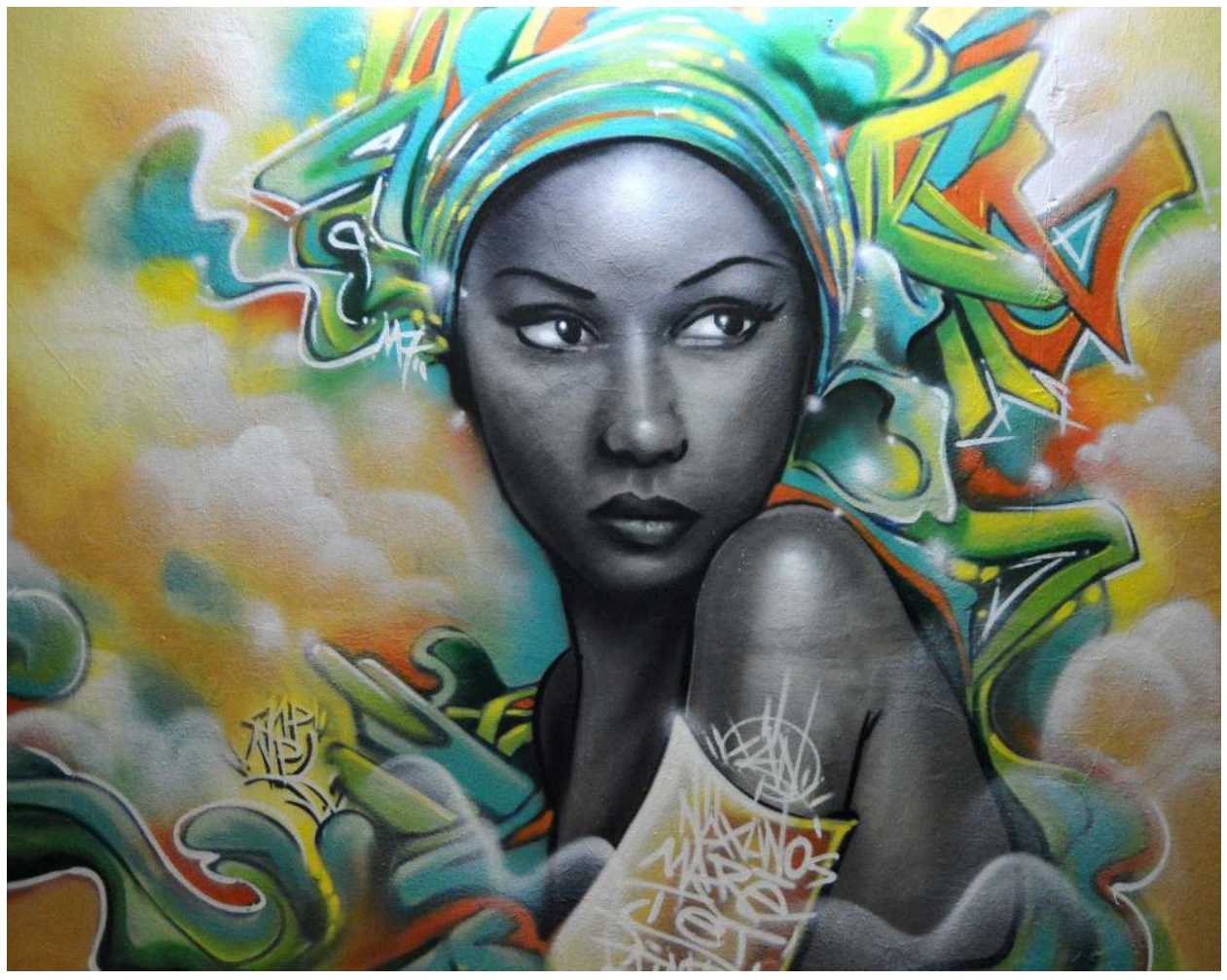

(24)

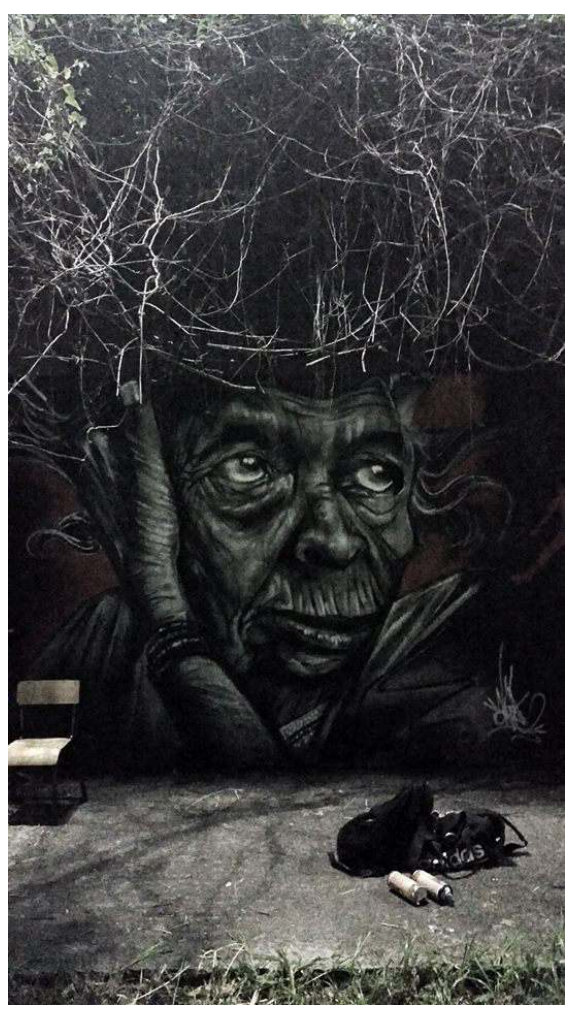


(25)

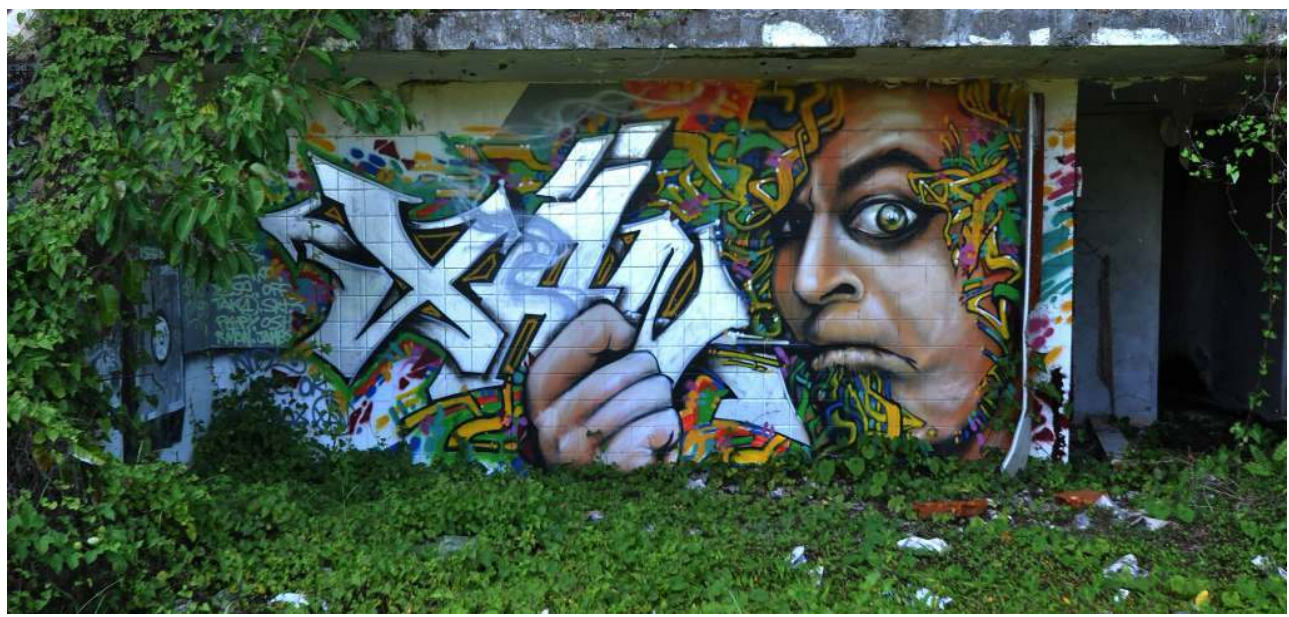

(26)

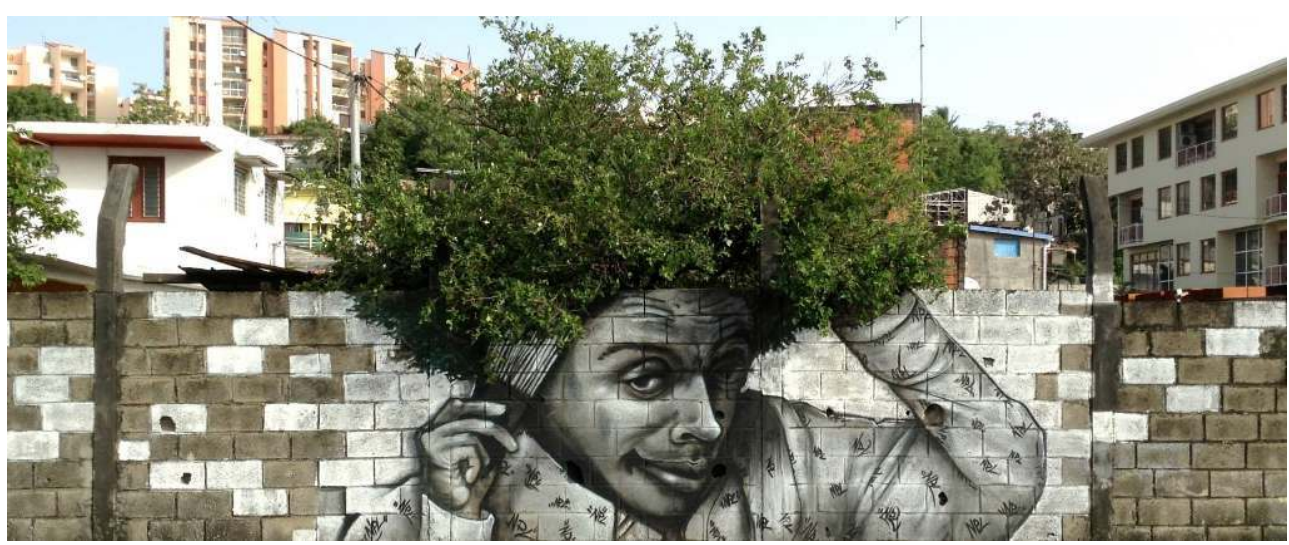

Un autre type d'interventions est pratiqué en Guadeloupe, réalisées dans diverses communes de l'île par le plasticien François Piquet (autodidacte, d'origine française, vivant en Guadeloupe depuis un certain nombre d'années) qui place ses collages quelque peu énigmatiques sur les murs des habitations, occupées ou non. Ses êtres hybrides (mihomme, mi-animal) ou composites par nature (27-28), investissent des lieux dans le cadre de son projet "Les archipels du moi ", sujet à travers lequel il traite d'une " archipélisation identitaire » et de la déconstruction des stéréotypes culturels ou ethniques (29). Ses personnages en noir et blanc, représentés à l'échelle une, sont parfois associés à des couleurs très codifiées rappelant celles de drapeaux (bleu, blanc, rouge, vert, jaune). (30) Elles sont appliquées en bandes verticales. Ce rapport monochrome bipolaire, l'absence de traits du visage ainsi que la composition hétéroclite qui caractérisent ces figures, produisent des images étranges (31). L'artiste prétend ici accentuer les contrastes culturels et démontrer une impossibilité de se déterminer sur l'origine ou la couleur de celui ou celle représentés (32). 
(27)

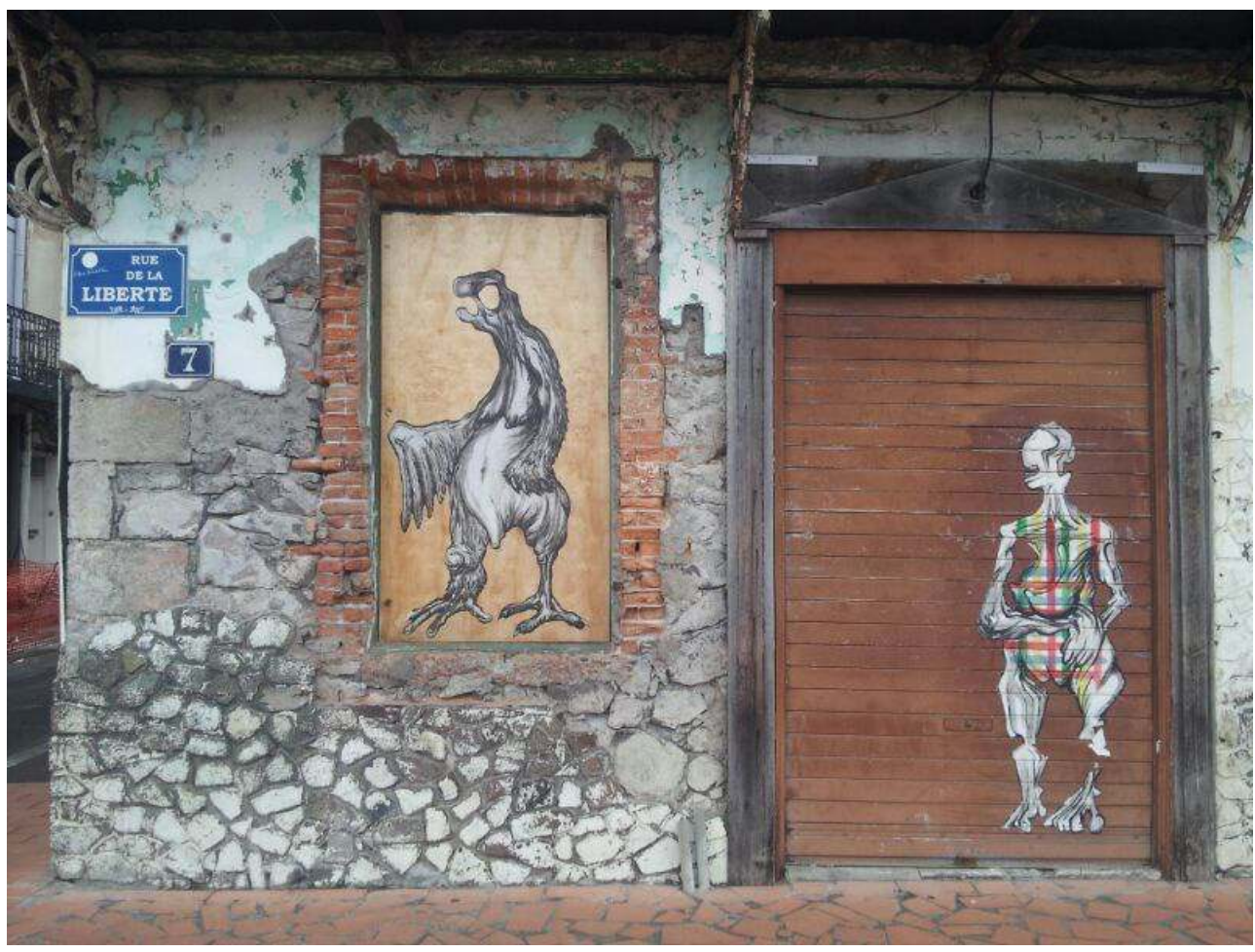

(28)

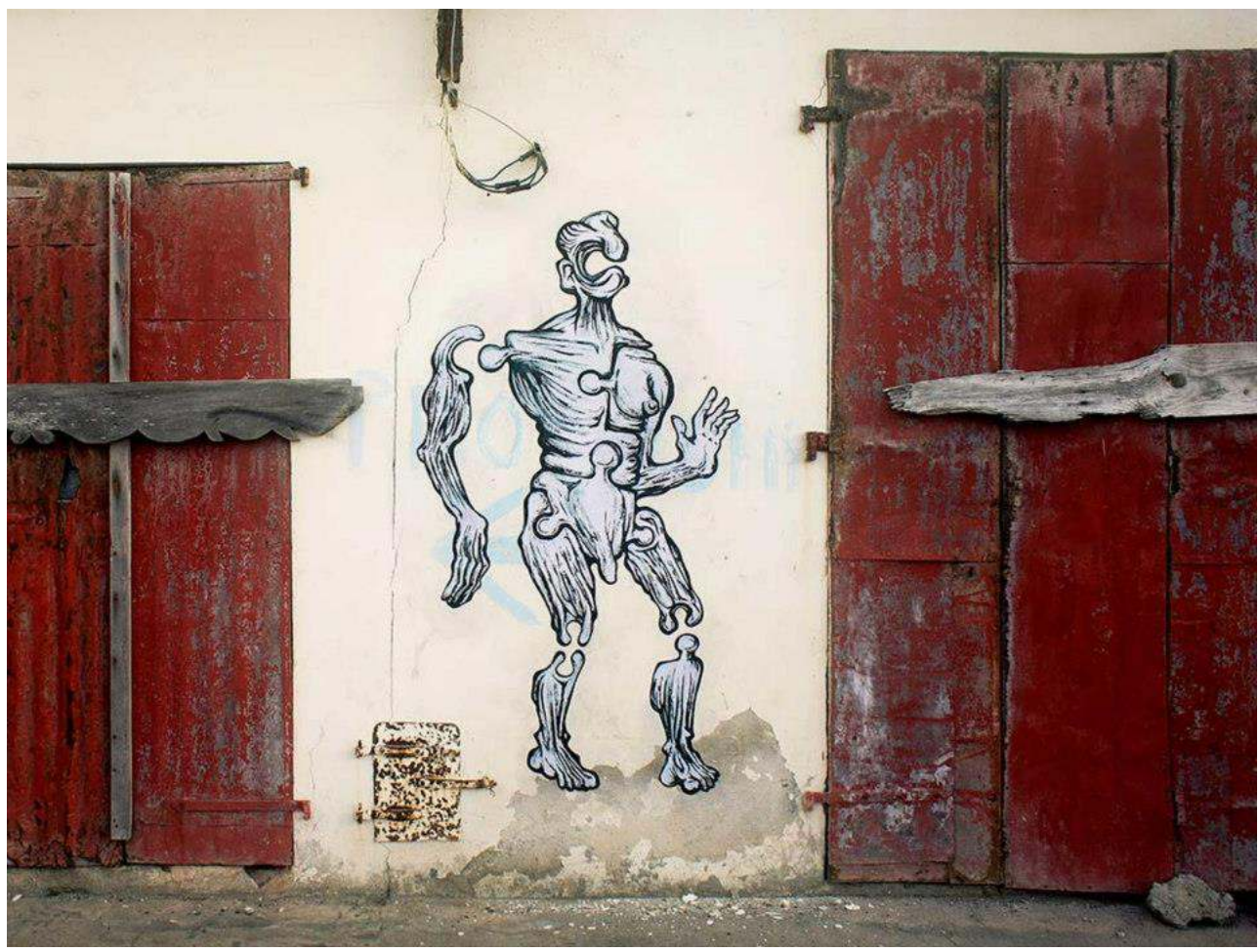


(29)

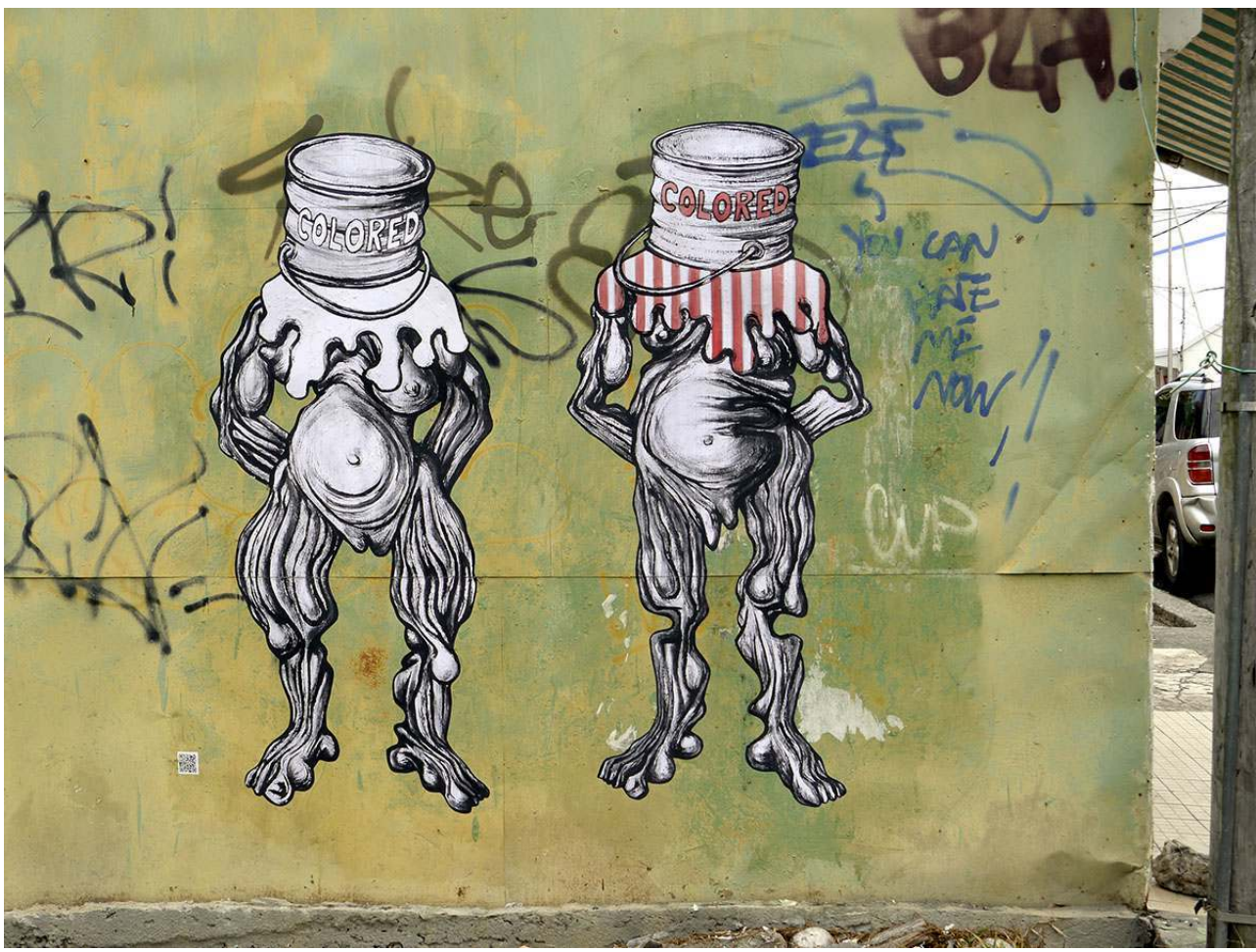

(30)

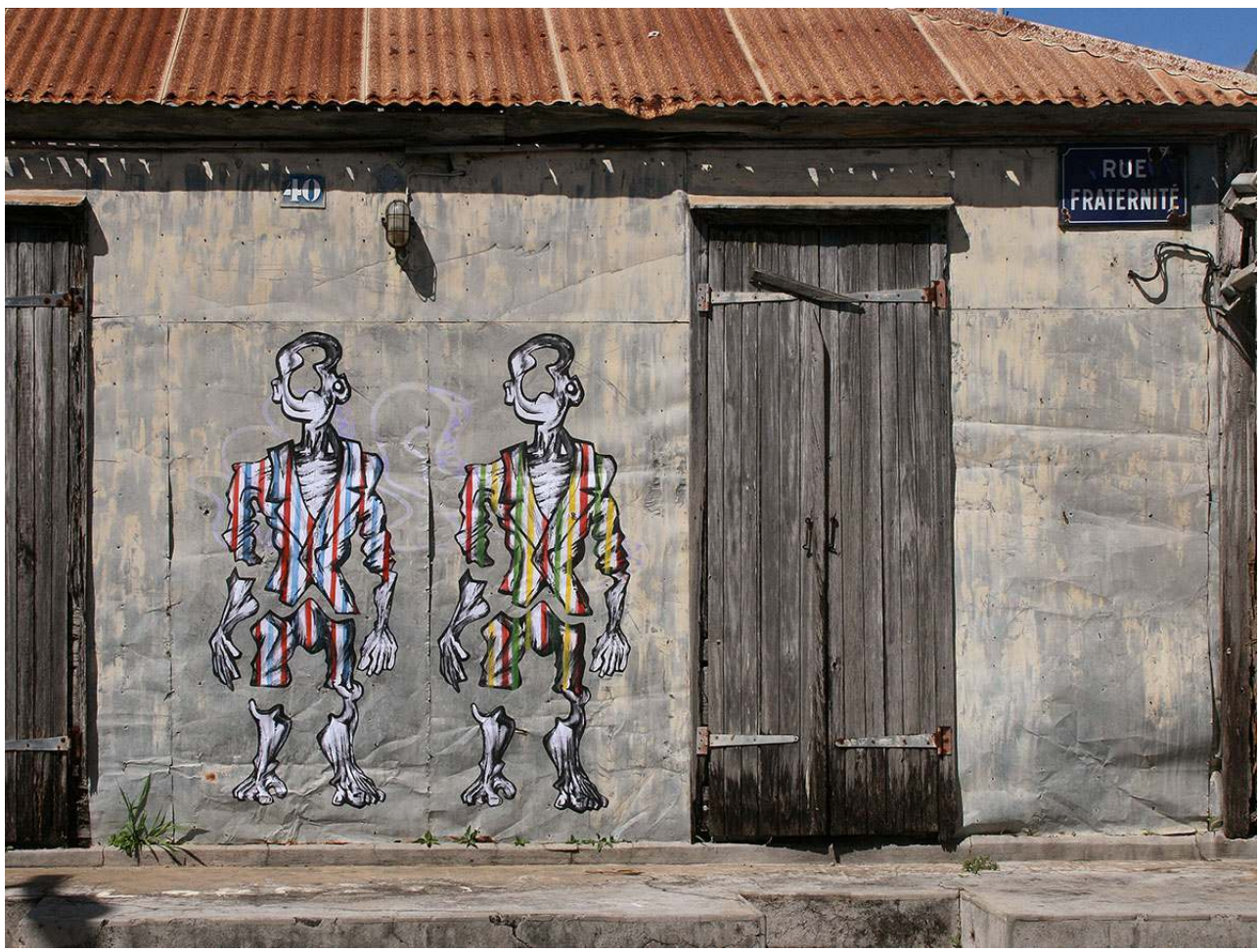


(31)

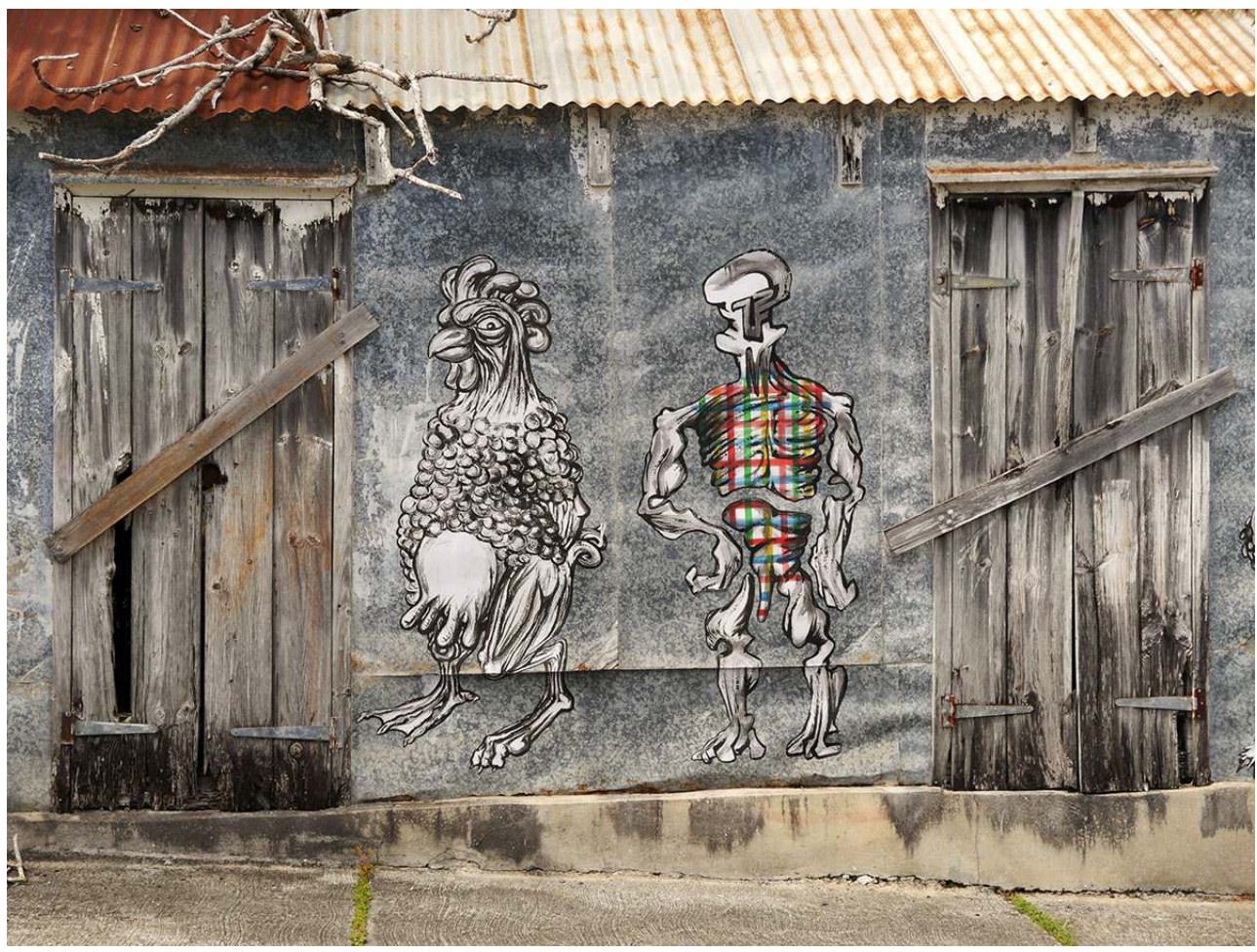

(32)

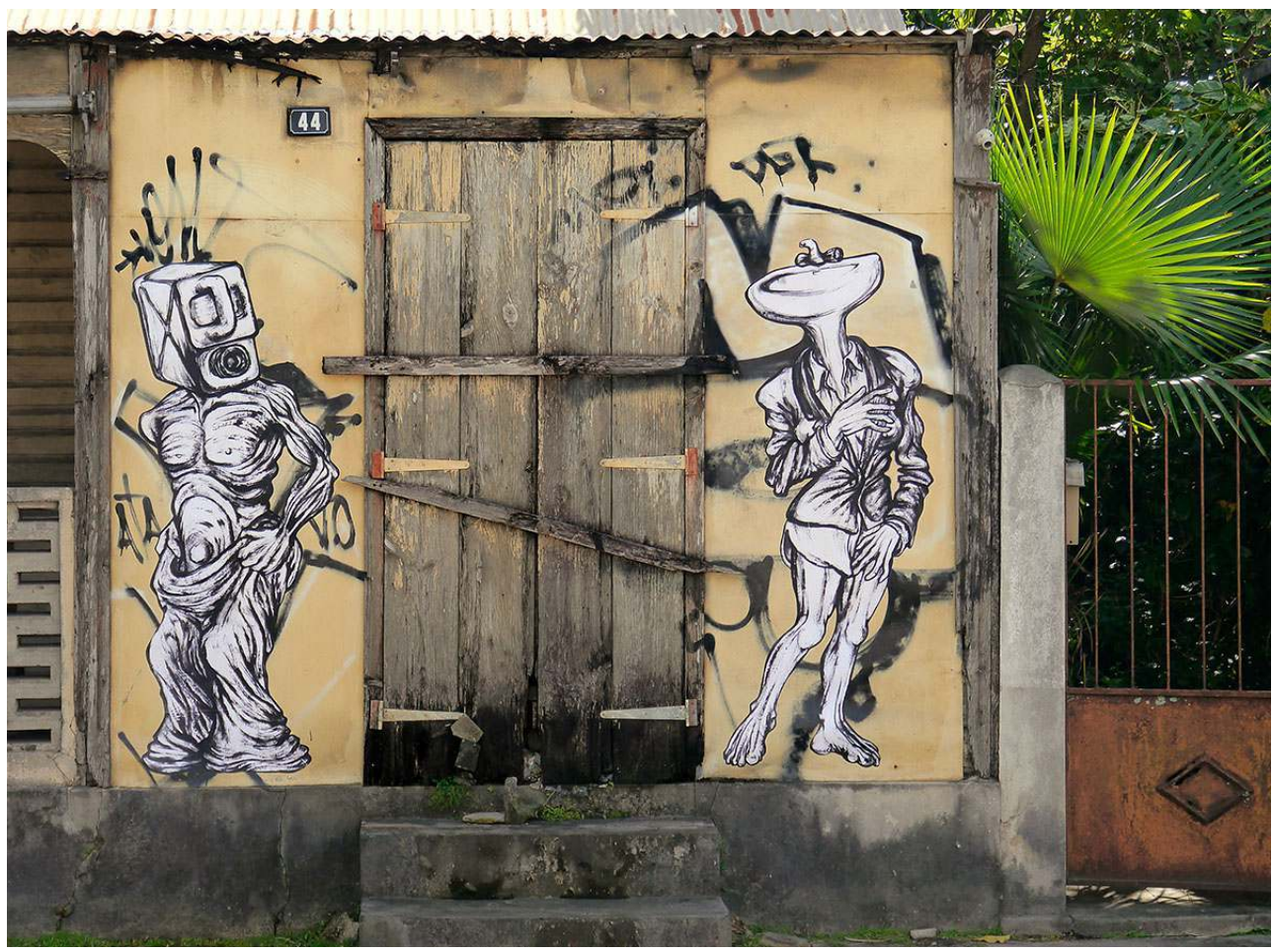

16 Ces collages s'inscrivent dans un rapport au temps et au lieu, ils sont placés à des endroits emblématiques, tenant compte du nom de la rue ou encore de l'histoire du lieu. Ces endroits sont investis de manière concertée avec les habitants (propriétaires, occupants, 
voisins). L'artiste compte ainsi rendre plus accessible l'art contemporain, tant par le lieu de monstration que par son propos. Les échanges, avec les usagers, précèdent et accompagnent les réalisations, ils participent également à la diffusion des clés de lecture de sa démarche.

Ainsi François Piquet place-t-il, au cœur des bourgs, une sorte de rébus urbain, un archipel de rencontres. Nous pouvons identifier ici une démarche qui démontre un parti pris plastique et conceptuel interrogeant la question du fragment et de l'hybridation.

Eddy Firmin, artiste d'origine guadeloupéenne, quant à lui, met en œuvre dans un de ses projets une série d'interventions sur d'anciennes cases créoles concentrées sur un territoire bien délimité qui est le bassin nord Grande-Terre, et qui recouvre les lieux de son enfance (33). Il réalise des peintures, modifiant l'aspect des cases, comme les recouvrant d'une nouvelle peau, à la surface de laquelle il produit une rencontre de deux éléments qui entrent en dialogue. Il établit ce que je qualifierais ici de code binaire révélant alors des problématiques qui sont en lien avec les spécificités du contexte géographique, historique, sociétal et culturel de l'île (34). S'il ne se considère pas comme un artiste du Street Art, il est indéniablement un plasticien qui use de medium et de dispositifs différents en fonction du discours qu'il souhaite véhiculer. Il veut se tenir à distance des institutions artistiques, il refuse même d'être catégorisé, voire réduit et assimilé à un genre artistique particulier. Il affirme d'ailleurs sa singularité par cette posture et son engagement politique. D'une certaine manière, il fait acte de résistance, par le biais de ses installations, voire de ses performances (35-36). Entre autres dispositifs, il va à la rencontre d'une conscience populaire, celle du peuple guadeloupéen, une mémoire collective qu'il tente de convoquer et d'interpeler. Du point de vue plastique, ce parti pris semble prendre la forme d'une sorte de code binaire lié à une multiplicité de facteurs que l'artiste évoque: «temporalité, lieu, caractère formel, matériau, signes visuels et textuel ${ }^{5}$ ». Cette mise en dialogue fait sens par la provocation mais surtout par le trouble que la rencontre suscite sur ce support spécifique, en cet espace et en ce lieu précis. Nous pourrions y voir s'articuler une dialectique entre l'ancien et le nouveau monde, le colon (l'Europe) et le "sauvage ", le catholicisme et l'animisme, le luxe et la pauvreté etc. "Généralement la contradiction, le trouble et la provocation en sont les effets les plus visibles ${ }^{6} »$ explique l'artiste. Eddy Firmin interroge ainsi son identité au regard de sa culture. Ce sont les marques et les bornes d'un récit séculaire sur l'art qu'il tente de relever et d'utiliser dans sa pratique. 
(33)

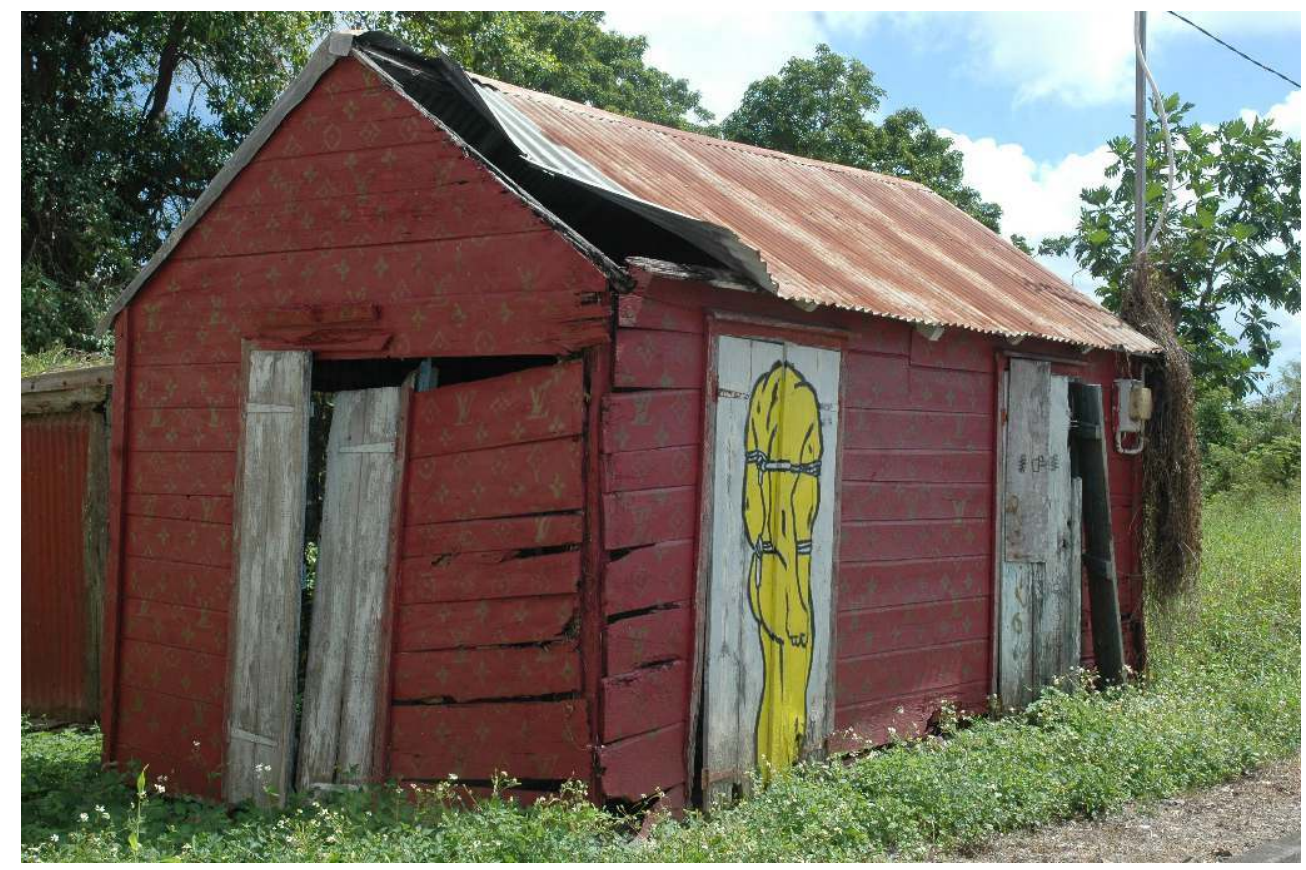

(34)

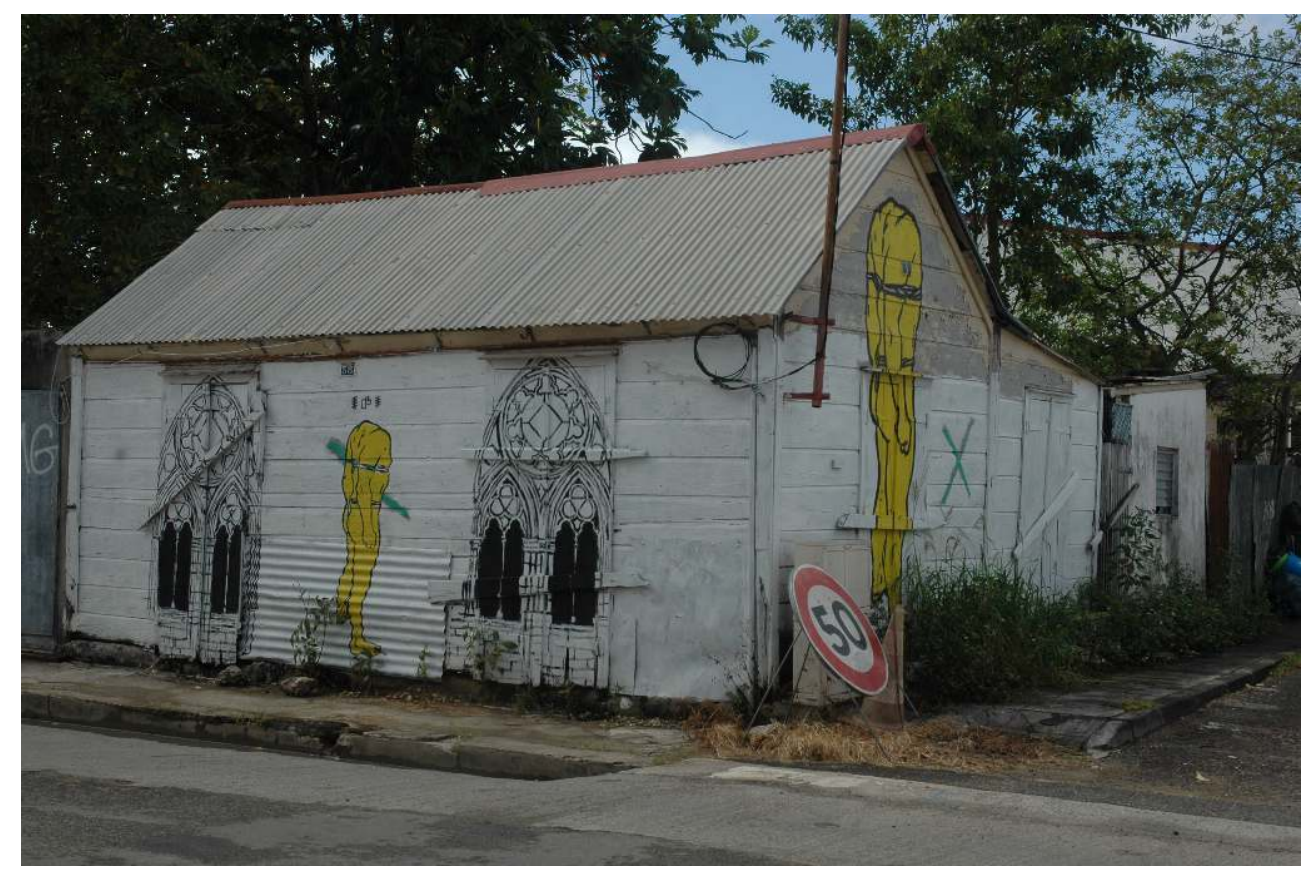


(35)

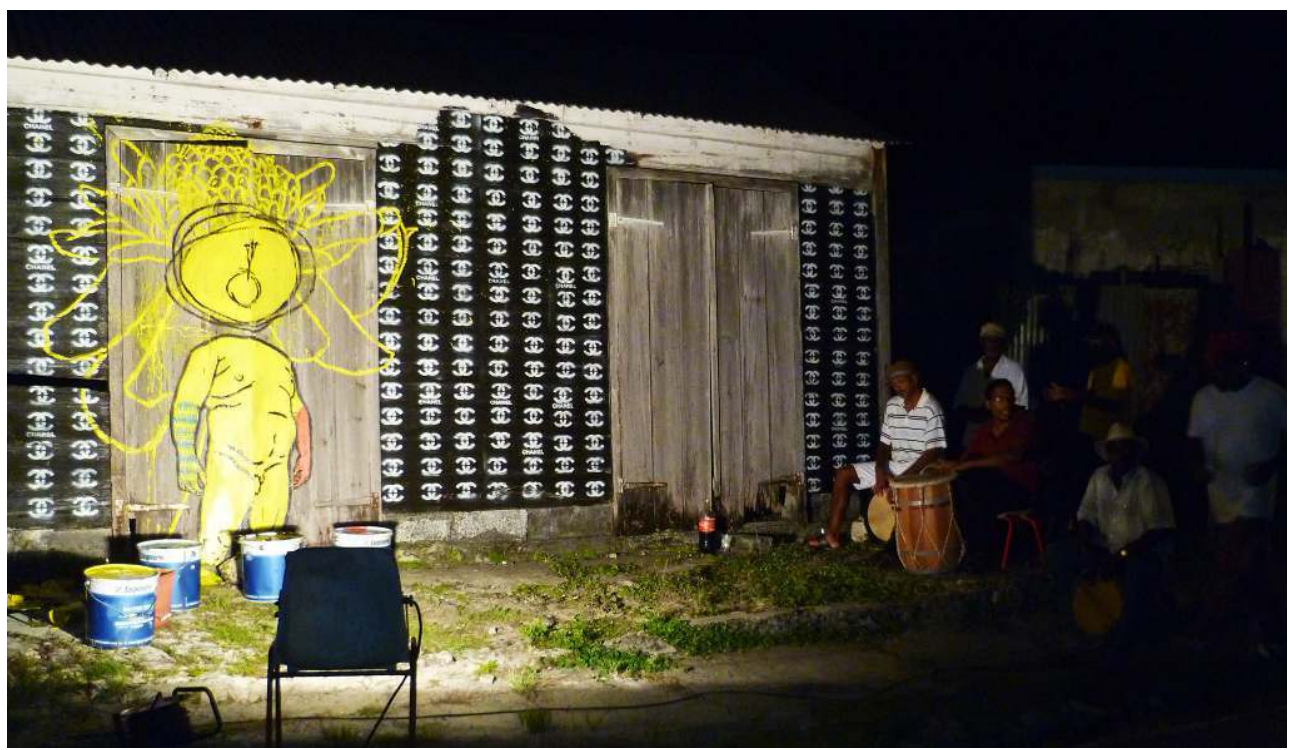

(36)

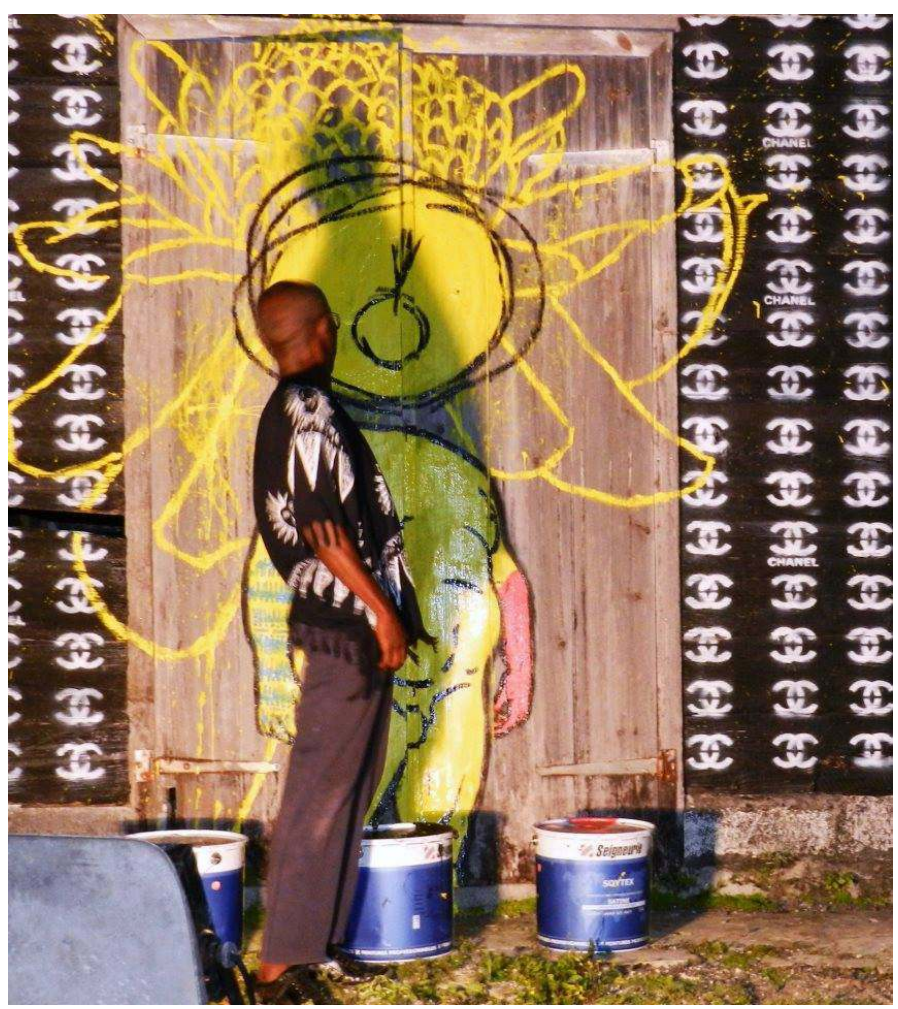

19 Ses fameuses «cases-horloges" comme il les appelle, ou "chronomètres culturels", traduisent l'idée de mesure ; une mesure à la fois temporelle et sociale. La case représente un « pilier magistral » dans la construction sociale antillaise, mais elle est surtout l'un des piliers de l'artiste, le lieu où son art s'est façonné. Plus qu'une intervention, une installation, ou une peinture, il s'agit d'une performance qui se met en scène autour de la case. Cette case, qui se veut ici un marqueur matériel de l'histoire et de la mémoire personnelle de l'artiste, également de la mémoire collective. 

îles où elle implante ses ramifications. Les styles et prérogatives de ces artistes sont aussi variés et complexes que la culture est plurielle et métissée. Les aspirations (culturelles, esthétiques, philosophiques, religieuses, politiques, etc.), les styles graphiques, les sujets, les couleurs, laissent transparaître les démarches singulières de chacun de ces artistes, et ce, qu'ils soient graffeurs ou plasticiens, que l'intervention soit légale ou non, relevant de la commande publique ou non.

21 Dans les deux cas, la population semble de plus en plus réceptive à cet art ou du moins plus encline à accepter le dialogue avec ces œuvres. Ces pratiques artistiques qui touchent progressivement l'espace urbain guadeloupéen et martiniquais, qui par le passé pouvaient effrayer, inquiéter, indigner les passants, aujourd'hui, gagne en reconnaissance, voire en admiration. Ces mêmes passants deviennent malgré eux spectateurs d'œuvres d'art hors du commun en quelque sorte. il irradie désormais, confronte la population à ces projections dont il porte les inscriptions, les traces, les amenant à s'émouvoir, à s'indigner, à être intrigués ou rester indifférents. Dans une telle démarche, quelque peu ambivalente, ces artistes souvent en marge d'un système (institution artistique, autorités et collectivités locales), troublent un certain ordre établi. Il est intéressant de voir comment aujourd'hui une société plutôt réticente auparavant, réceptionne désormais avec un certain intérêt ces fresques et ces interventions. Bien qu'éphémères, elles laissent malgré tout des traces, révélant des strates de mémoire alors enfouies, pointant du doigt des aspects actuels d'une culture, ou encore exprimant simplement des aspirations plus personnelles. pas toujours en adéquation avec la société et les institutions, mais sera intégré par une population dont elle incarne une forme de représentation, comme témoin d'un quotidien, d'une histoire, d'une culture, de troubles et d'aspirations diverses, etc. Il ne s'agit donc pas d'art pour l'art, mais bien de modes d'expressions et de communications artistiques qui se veulent désormais au service de l'homme dans la ville; un art à l'image des habitants et des passants. C'est un véritable travail de mémoire qui se met en place ici, mémoire en constante «construction » ou « reconstruction» et à partir de laquelle se façonne une identité individuelle et collective.

\section{BIBLIOGRAPHY}

Berry, A.- C. (2015), « Le Street art en Martinique. Gros plan sur le graffiti », in Recherches en Esthétique, $\mathrm{n}^{\circ} 20$, «Créations insulaires ».

Chancé, D. (2005) Histoire des littératures antillaises, Paris, Ellipses, coll. « Littérature Des Cinq Continents».

Le Clézio, J.M.G. (2009) in Kréyol Factory: Des artistes interrogent les identités créoles, Paris, Gallimard. Stanislas, J. (2011), Nou Yorkers, production 4KG.

Cahiers de Narratologie, 29 | 2015 


\section{NOTES}

1. Dominique Chancé, Histoire des littératures antillaises, Paris, Ellipses, coll. « Littérature Des Cinq Continents ", 2005, p. 7.

2. Jean-Marie Gustave Le Clézio, in Kréyol Factory: Des artistes interrogent les identités créoles, Paris, Gallimard, 2009, p. 4.

3. Janluk Stanislas, Nou Yorkers, production 4KG, 2011

4. Berry Anne-Catherine, «Le Street art en Martinique. Gros plan sur le graffiti », in Recherche en Esthétique, $\mathrm{n}^{\circ} 20$, « Créations insulaires », janvier 2015, pp. 79-90.

5. Entretien avec Eddy Firmin, 28 juillet 2015

6. Entretien avec Eddy Firmin, 28 juillet 2015.

\section{ABSTRACTS}

This paper examines artistic practises in the urban public space of the French Antilles, especially in Martinique and Guadeloupe. Since the end of the 1980, this art form has appeared on the street walls of both islands and has progressively spread. Tags and graffitis - which seemed rather punctual and isolated incidents-appeared first, later followed by murals, collages or even installations. Although some of these practises are still occasional, their presence in the urban landscape creates a real impact, be it a visual, aesthetic or semantic one. Most importantly, they seem to tell about the special features of the islands. Whether the artists are self-taught or professionally trained, they testify to their particular regional context whose complexity comes from its plurality. Some are truly artistically engaged, showing their belief in the concept of a West Indian identity. Such contributions tend to reveal how deeply rooted in the idea of a plural society this type of art is. As a blending of different ethnies, the Creole culture creates the environment where artworks can emerge and shares a special link with them. How can these works testify to the singularities of this culture? What do they tell about it and what feelings can they arouse?

Regard sur les pratiques artistiques s'inscrivant dans l'espace public urbain, aux Antilles, cet article concerne particulièrement la Martinique et la Guadeloupe. Depuis la fin des années 1980 une forme d'art se dessine sur les façades des deux iles, et prolifère progressivement. Les tags et les graffitis, plutôt ponctuels et isolés, font l'objet des premières interventions. Ils côtoient plus tardivement des peintures murales, des collages, voire des installations. Si certaines de ces pratiques artistiques se font encore rares, lorsqu'elles surgissent dans le paysage urbain, elles génèrent un impact certain qu'il soit visuel, esthétique ou sémantique. Et surtout elles semblent révéler les spécificités et singularités de leur région insulaire. Ainsi, qu'ils soient autodidactes ou de formations artistiques, ces artistes témoignent de leur ancrage dans un contexte régional complexe, car pluriel. Certains témoignent véritablement d'une démarche artistique engagée, en exposant un parti pris en lien avec l'idée d'une identité antillaise. Cette contribution tend à montrer comment l'art dont il est question ici appartient à un concept de société plurielle. Cette culture créole, faite de métissages, façonne l'environnement (physique et immatériel) dans lequel émerge l'œuvre mais également avec lequel elle entretient un lien particulier. Comment ces 
réalisations rendent-elles compte des spécificités de cette culture ? Que semblent-elles révéler? Que peuvent-elles éveiller?

INDEX

Mots-clés: street art, graffiti, peinture murale, installation, espace public, lieu, insularité, identité, créole, métissage

Geographical index: Petites Antilles Françaises

\section{AUTHOR}

\section{ANNE-CATHERINE BERRY}

Professeure certifiée en Arts plastiques, en poste à l'ESPE de la Martinique, où elle enseigne dans le cadre de la préparation au CAPES d'Arts plastiques. Doctorante en arts caribéens à l'Université des Antilles, rattachée au Centre d'Etudes et de Recherches en Esthétique et Arts Plastiques (CEREAP) équipe interne du Centre de Recherches Interdisciplinaires en Lettres, Langues, Art et Sciences Humaines (CRILLASH), ses recherches portent sur la fragmentation du corps dans les arts plastiques des Petites Antilles françaises. Participe depuis 2004 aux conférences et publications du CEREAP, par des recensions et des articles publiés dans les revues Recherches en Esthétique et Gaïac, articles portant essentiellement sur le Street art. 